\title{
Inversión pública y crecimiento económico: Hacia una nueva perspectiva de la función del gobierno
}

José Luis Hernández Mota*

\section{RESUMEN}

En el desarrollo del trabajo se pretende mostrar que el ahorro no es un prerrequisito para generar riqueza mediante su canalización a la inversión. Por lo contrario, se analiza y construye un modelo cuyo principio radica en la proposición de que la riqueza no depende de la capacidad de generación de ahorro ex ante, sino de que las políticas públicas y las acciones privadas creen las condiciones propicias para la inversión productiva. En este sentido, se introduce al gasto público productivo para mostrar que éste no generará riqueza en tanto no contribuya a incrementar las oportunidades de inversión rentables, por tanto, la política de gasto público debe evitar su desperdicio en usos no rentables, como el financiamiento a un mayor consumo, público y/o privado, y en su lugar destinarse al fomento de las condiciones favorables para obtener una mayor productividad de la inversión, pública o privada, no sustitutiva.

Palabras clave: crecimiento económico, riqueza, inversión pública, gasto público productivo.

Clasificación JEL: E62, H30, H40, H54, O41.

\begin{abstract}
In the paper is intended to show savings is not a prerequisite to generate wealth through his pipe investment. On the contrary, analyses and builds a model whose principle lies in the proposition that wealth does not depend on the way former before, but of public policies and private actions to create conditions conducive to productive investment savings generating capacity. In this sense, is introduced to the productive public expenditure to show that it will not generate wealth insofar as it does not contribute to increase profitable investment opportunities, therefore, public spending policy avoid their waste in unprofitable uses as financing to increased consumption, public and/or private, and instead, is intended for the promotion of advantageous for productive investment, public or private, no substitutive.
\end{abstract}

Key words: economic growth, wealth, public investment, expenditure public productive. Clasificación JEL: E62, H30, H40, H54, O41.

${ }^{*}$ Doctorante del Programa Integrado de Maestría y Doctorado en Ciencias Económicas de la UAM. Correo electrónico: jlhernandez@correo.xoc.uam.mx 


\section{INTRODUCCIÓN}

Un tema constante dentro de la bibliografía del crecimiento económico endógeno es responder la cuestión compleja y controversial acerca de que si el gasto público productivo (que se refleja en la denominada inversión pública) y la inversión privada son complementarios, sustitutos o, como se asume en otros modelos macroeconómicos sobre el crecimiento, independientes uno del otro. Este renovado interés se debe a los resultados obtenidos por Aschauer (1989a), Barro (1990), Holtz-Eakin (1992), Devarajan y Zou (1994), Lin (1994), Olson (1996), Nazmi y Ramírez (1997 y 2003), Lächler y Aschauer (1998), Albala-Bertrand y Mamatzakis (2001), Ramírez (2007), entre otros, los cuales han intentado clarificar el potencial impacto del gasto público productivo en el crecimiento económico de largo plazo, a partir de situar a los determinantes de la inversión, pública o privada como generadores de riqueza, y no a los del ahorro, como tradicionalmente se asume.

La racionalidad económica de lo anteriormente expuesto reside en la idea de que el gasto público productivo, al reflejarse en inversión pública, está dirigido a la producción de bienes y servicios que el sector privado no produciría por el incremento sustancial de sus costos o por los beneficios compartidos que ocasionaría su adquisición. Sin embargo, este tipo de bienes denominados públicos son de importancia decisiva para el correcto funcionamiento de una economía de mercado porque ellos tienden a generar una gran y amplia derrama de beneficios. ${ }^{1}$ Por ejemplo, además de que el gasto público en inversión para la creación y/o operación de infraestructura económica y social tiende a completar la formación de capital privado, facilitando la implantación y realización de los planes de inversión privados -mediante la disminución y, en su caso, eliminación de costos de transacción presentes en los transportes, las comunicaciones o la educación y capacitación de la población-, su costo de provisión es menor a su contribución total (Esfahani y Ramírez, 2003). Así, este tipo de gasto en inversión pública puede tener un efecto indirecto sobre la formación de capital privado en tanto que no sólo permite incrementar la demanda agregada de bienes y servicios producidos por el sector privado, sino que también influye en las expectativas de los inversores privados sobre ventas y beneficios futuros.

\footnotetext{
${ }^{1}$ La explicación clásica para las fallas de mercado y la necesidad de la intervención estatal para la provisión social de capital, sobre todo en países en desarrollo, se encuentra en Scitovsky (1954) y Nurske (1953).
} 
En consecuencia, si tradicionalmente el crecimiento económico se considera ligado a fuerzas externas, como los factores demográficos o, en su caso, a la eficiencia de la fuerza de trabajo (pues es ampliamente reconocido que éstos permiten un crecimiento de la productividad y por tanto un incremento de la producción), entonces las únicas políticas macroeconómicas que podrían contribuir eficazmente a un crecimiento económico de largo plazo serían aquellas que podrían incrementar la eficiencia de los factores productivos. ${ }^{2}$ Por esta razón, últimamente el diseño de la inversión pública en infraestructura económica y social (aeropuertos, carreteras, puertos, servicios eléctricos, gas, agua, salud y educación, entre otros) de los países con crecimiento, se ha enfocado en generar incrementos tanto en la productividad laboral como en la productividad total de los factores y no únicamente en la creación o mantenimiento de la infraestructura que no genera condiciones para el crecimiento de la productividad.

Sin embargo, a pesar de estos desarrollos recientes en el campo de la teoría del crecimiento económico, muchos países en desarrollo continúan renuentes a cambiar radicalmente su estrategia de desarrollo basada en la menor participación del Estado por medio de la reorientación de políticas en pro del mercado y por la disminución del gasto público, lo que ha generado reducciones en los niveles de inversión pública para la creación de infraestructura económica y social, aun cuando se ha mostrado ${ }^{3}$ que estas inversiones públicas constituyen un gasto productivo que generalmente complementan y no sustituyen a la inversión privada, disminuyendo los posibles beneficios que pudieran ser obtenidos por los procesos de privatización y liberalización de las economías en cuestión.

A la luz de lo anterior, el presente documento examina la controvertida cuestión de que si la restricción de ahorro es un prerrequisito para generar riqueza por medio de la inversión, como lo sugiere el enfoque tradicional del crecimiento económico. Para ello, se postula, en sentido contrario al enfoque tradicional, que la causalidad actual que prevalece en las economías para la generación de riqueza va de la inversión al ahorro y no a la inversa. Esto implica que, siguiendo los resultados obtenidos por los desarrollos recientes en la teoría del

\footnotetext{
${ }^{2}$ Esto puede ser obtenido mediante el diseño explícito de políticas de gasto público que se orienten a impactar directamente en la eficiencia de los factores productivos, por lo que es condición necesaria que los presupuestos públicos y el gasto derivado de ellos se destinen a un fin productivo.

${ }^{3}$ Al respecto véase los estudios de Lucas (1988), Aschauer (1989a), Barro (1990), Lin (1994), los cuales además de la evidencia empírica, tienen una sólida base teórica que soporta sus conclusiones.
} 
crecimiento económico endógeno, son la eficiencia, la innovación y el cambio tecnológico los determinantes de una mayor productividad de la inversión, lo que genera el crecimiento económico. Sin embargo, dada la restricción de inversión privada prevaleciente debida a flujos de capital restringidos, que se presenta sobre todo en las economías emergentes, ${ }^{4} \mathrm{y}$ ante la imposibilidad del sector privado para aportar los recursos para la inversión, si se parte de la hipótesis de que el sector público es quien puede proveer dichos recursos por medio de un gasto público productivo, entonces podría generarse la causalidad gasto público productivo (que puede verse como inversión pública, como más adelante se explica) que genera ingreso mediante el incremento de la demanda agregada, parte del cual se convierte en ahorro que puede utilizarse para financiar inversión privada en proyectos productivos generadores de riqueza. Esto podrá ir incrementando las fuentes de ingreso de los factores productivos y generar así recursos tributarios que financien el gasto público productivo, convirtiéndose así en un círculo virtuoso.

Esto implica un nuevo concepto sobre la función del Estado en la economía, soslayando falsos dilemas sobre la lucha Estado-mercado, pues lo que se postula es que más que la restricción de ahorro, la restricción que impera en una economía con insuficiente flujo de capital para generar mayor riqueza es su incapacidad para generar proyectos rentables de inversión, y es en este punto en particular donde la función del Estado tiene un papel de vital importancia. El Estado, utilizando el gasto público productivo, puede generar las condiciones humanas y físicas para emprender proyectos rentables de inversión, que tenderán por sí mismos a encontrar sus medios de financiamiento (interno o externo), generando recursos suficientes para pagarse solos, como requisito fundamental de su rentabilidad, provocando así un incremento de la riqueza neta. En consecuencia, el crecimiento y la inversión dependen no tanto de la capacidad de generar ahorro ex ante, sino de que el gobierno y sociedad (el Estado en sí) creen las condiciones propicias para la inversión productiva, lo cual implica que la eficacia de las acciones de la política económica para impulsar el crecimiento económico

\footnotetext{
${ }^{4}$ La categoría de economía o mercado emergente nace formalmente a mediados de la década de los setenta del siglo pasado, impulsada por la International Finance Corporation del Banco Mundial, y trata en general de economías en vías de desarrollo pero atractivas en cuanto a la inversión extranjera (tanto de cartera como directa), aunque con mayor nivel de riesgo (por la volatilidad de sus mercados financieros) que las economías desarrolladas, por lo cual el financiamiento de sus diferentes proyectos de inversión en los mercados de capitales internacionales suele llevar asociada una penalización conocida como prima de riesgo.
} 
depende no tanto de su efecto en el ahorro, sino del que tenga sobre la inversión. Lo anterior es el objeto de estudio del presente trabajo, considerando que los nuevos enfoques del crecimiento económico sitúan a los determinantes de la inversión y no a los del ahorro como los generadores de riqueza, y que los análisis tratados sólo han sido relevantes para explicar las diferencias en las experiencias de crecimiento entre los diversos países pero no especifican la relación entre éstos y las políticas y estrategias de crecimiento implantadas por los gobiernos, parte fundamental no explicada y, en algunos casos, ni siquiera considerada. ${ }^{5}$

La sección I se inicia con una revisión de la bibliografía referente a la relación existente entre la inversión pública (como expresión más nítida del gasto público productivo, que es la variable considerada por los autores citados en párrafos anteriores) y la hipótesis de complementariedad, que sirve de fundamento para desarrollar un modelo teórico en el cual se incluye al acervo de capital público como un argumento de la función producción. La sección II aborda la nueva función del Estado en el proceso de generación de riqueza, según el contexto de los nuevos enfoques de la teoría del crecimiento económico y de la nueva concepción del gasto público indicada anteriormente. Posteriormente, en la sección III se presenta un modelo de dos sectores que versa sobre la relación entre el capital público y el crecimiento económico, donde se destaca la causalidad entre inversión y crecimiento, y se plantea que ante situaciones de restricciones de ahorro la inversión pública, producto del gasto público productivo, tiene una función complementaria respecto a la inversión privada, y por tanto puede crear riqueza a partir de la generación de externalidades positivas en la producción sin que, por otro lado, se generen desequilibrios fiscales. En la sección IV se presentan algunos resultados al respecto de la experiencia en la economía mexicana durante el periodo 1980-2008, y al final se presentan las conclusiones.

\section{LA INVERSIÓN PÚBLICA Y LA HIPÓTESIS DE COMPLEMENTARIEDAD}

Desde la aparición del trabajo seminal de Arrow y Kurz (1970), se despertó el interés en el análisis de la relación entre la política fiscal y la tasa de crecimiento de una economía. Su principal contribución radicó en desarrollar un modelo en el que los consumidores derivan su utilidad tanto del consumo privado como del

\footnotetext{
${ }^{5}$ Por ejemplo, Olson (1996) encontró empíricamente que factores tales como la calidad del gobierno, la capacidad de la política económica para generar incentivos para la inversión y la actividad económica, la regulación que fomenta la competencia y los derechos de propiedad con reglas claras son factores que determinan al crecimiento más que el ahorro interno.
} 
acervo de capital público generado por los flujos de inversión pública. Asimismo, los beneficios de la producción privada también son generados por el uso de dicho acervo. Sin embargo, Arrow y Kurz suponen que toda la inversión pública es productiva, por lo cual no es necesario hacer una distinción entre gasto público productivo y no productivo, y dado que formulan un modelo neoclásico de crecimiento, dicho gasto público sólo afecta la tasa de crecimiento transicional de la economía mientras la tasa de crecimiento en estado estacionario permanece inalterada.

Con la aparición y desarrollo de la teoría del crecimiento endógeno (Romer, 1986, y Lucas, 1988), se despertó el interés por desarrollar modelos en los que se vinculara el gasto público con la tasa de crecimiento de largo plazo de una economía. A este respecto, Barro (1990), continuando con lo presentado por Aschauer (1989 a y c), introduce el concepto de gasto público productivo como un gasto que realiza el sector público en creación de infraestructura económica y que genera efectos en la producción misma o en la productividad de los factores de la producción, con la particularidad de que dicho gasto es complementario a la producción privada, por lo cual lo incluyen como un argumento de la función producción. Sin embargo, al igual que Arrow y Kurz para la inversión pública, Barro y Aschauer suponen que todo el gasto público incluido dentro de la función producción es productivo, encontrando evidencia empírica para una relación positiva entre la inversión pública (como expresión nítida del gasto público productivo utilizado por ambos autores) y el crecimiento del producto.

Esto contrasta ampliamente con la tradición neoclásica de considerar que la inversión pública desplaza a la inversión privada, por lo cual se inhibe el crecimiento futuro y la productividad. Sin embargo, Devarajan y Zou (1994) observan que los efectos negativos, directos e indirectos, de la inversión pública, en realidad son contrastantes, dependiendo de la forma en que se financie dicho gasto y de la estructura del sistema financiero. Ahora bien, la inclusión de la inversión pública en particular o del gasto público productivo en general como un argumento de la función producción, es posible en tanto que las inversiones en infraestructura económica y/o social facilitan la implantación y realización de los planes de inversión de los agentes privados, eliminando costos y barreras de transacciones y de capacitación y educación.

Asimismo, la inversión pública también tiene un efecto indirecto en la formación de capital privado y por consiguiente en el crecimiento económico, pero no sólo por el aumento de la demanda agregada en bienes y servicios produ- 
cidos por el sector privado, ${ }^{6}$ sino también por la influencia en los beneficios futuros y en las expectativas de ventas de los inversionistas privados. Por tanto, bajo estas consideraciones puede argumentarse que la inversión pública en infraestructura económica y social (o gasto público productivo), genera incrementos en la productividad total de los factores en general y en la productividad laboral en particular, creando asimismo un acervo de capital público que está a disposición de cualquier agente productivo como bien público, pero con la particularidad de que dicho bien público no es sólo para su consumo de corto plazo sino que lo puede utilizar para incrementar sus capacidades productivas de largo plazo. ${ }^{7}$

Por otra parte, siguiendo la línea de investigación desarrollada inicialmente por Barth y Cordes (1980) y Aschauer (1989b) se desarrolló la "hipótesis de complementariedad de la inversión pública" con el fundamento de incluir el acervo de capital público proveniente de los flujos de inversión pública, como un argumento de la función producción neoclásica para analizar los efectos de la inversión pública en el producto, la productividad marginal de los factores y en el capital privado, y se justificó mediante la idea de que la inversión pública genera derramas de beneficios para la economía de mercado, por lo cual el impacto de la inversión pública en el gasto en la inversión privada y el crecimiento económico puede ser analizada en términos de la siguiente función producción:

$$
\begin{aligned}
& Y_{t}=F\left[\left(L_{t}, K_{p t}, K_{g t}\right) ; \alpha_{i}\right]+\varepsilon \\
& F_{1}, F_{2}>0 ; F_{11}, F_{22}<0 ; F_{12}>0 \\
& F_{3} \leq 0 ; F_{23} \leq 0 ; F_{13} \frac{\partial}{\partial_{1}} 0,
\end{aligned}
$$

donde $Y$ es el nivel del producto real, $L$ el empleo, $K_{p}$ es el acervo de capital privado, $K_{g}$ el acervo de capital público, $\alpha_{i}$ representa otras variables que pueden ser incorporadas a la función producción para explicar el nivel del producto interno bruto, como las exportaciones de manufacturas, la provisión de crédito real

\footnotetext{
${ }^{6}$ Mecanismo desarrollado plenamente por los modelos keynesianos.

${ }^{7}$ En este sentido, el trabajo de Esfahani y Ramírez (2003) aporta evidencia empírica respecto a los efectos positivos de la infraestructura generada por el gasto público en el crecimiento económico, destacando que las diferencias entre las tasas de crecimiento económico obtenidas por los países radica en la calidad de sus instituciones para asignar y administrar dicho gasto, más que en el gasto mismo, por lo cual un requisito necesario para lograr la efectividad de la política gubernamental es la reforma institucional y organizacional más que la simple asignación de recursos a proyectos de infraestructura.
} 
al sector privado y los gastos de consumo del gobierno (Lin, 1994), en tanto $\varepsilon$ es un parámetro de cambio de la función producción.

La inclusión del acervo de capital público en la función producción tiene tres efectos, siempre que se trate a éste como un insumo adicional de la función producción. Primero, cuando el capital público y el capital privado son complementarios, un aumento en el acervo de capital público incrementará el producto directamente, de la misma manera que lo hiciera cualquier otro factor de la producción $\left(F_{3}>0\right)$. Segundo, ese mismo incremento elevará la productividad marginal del acervo de capital privado $\left(F_{23}>0\right)$ en relación con la tasa de interés real. Tercero, también incrementará la productividad marginal del factor trabajo aumentando el monto de capital público y privado por trabajador $\left(F_{13}\right.$ y $\left.F_{12}>0\right)$.

En todos estos casos se presupone que el sector público provee eficientemente los bienes públicos que tiene que producir mediante la inversión pública en sectores no competitivos de la economía. Si, por lo contrario, el capital público y privado son sustitutos directos, prevalecen entonces los efectos del desplazamiento de la inversión privada por la inversión pública, pues un incremento de esta última, que permite incrementar el acervo de capital público, tiene dos efectos: un efecto directo positivo y uno contrario, cuya condición es: $\left[\left(F_{3}+F_{13}\right)+\right.$ $\left.F_{23}-F_{12}\right]<0$. Esto es debido a que la inversión pública compite directamente por fondos y mercado con la inversión privada en sectores competitivos, en lugar de interactuar. Por último, cuando tanto el capital público como el capital privado son independientes uno de otro $\left(F_{23}=0\right)$, un incremento en la inversión pública generará un efecto positivo directo en el producto.

\section{LA FUNCIÓN DEL ESTADO Y EL PROCESO DE INVERSIÓN}

Después de la segunda Guerra Mundial, durante muchos años la inversión pública se manejó de manera estratégica para propiciar un crecimiento económico como parte del proceso de reconstrucción, en el caso de los países beligerantes, o bien del proceso de creación de la infraestructura económica mínima indispensable para iniciar el despegue del crecimiento económico de los países atrasados (no desarrollados).

En América Latina, la estrategia desarrollada es conocida como industrialización por sustitución de importaciones (ISI). Los responsables de la política económica de los países que adoptaron esta estrategia tenían como principio fundamental el que la inversión desempeñaba un papel decisivo no sólo como componente de la demanda agregada, sino también en términos de poder determinar 
el tamaño del acervo de capital de la economía para que pudiera actuar como fuente futura del crecimiento económico. Sin embargo, dada la necesidad de recursos de los inversionistas privados para financiar sus principales proyectos de inversión, y la insuficiencia tanto de infraestructura económica y social como del desarrollo de mercados, seguridad e información, la decisión de política económica fue que el gobierno destinara una parte considerable del gasto público a invertir en infraestructura e industria básica para poder producir bienes y servicios públicos que generaran una derrama de efectos positivos sobre la economía, afectando la tasa de crecimiento y permitiendo, ante la falta de ahorro interno, un financiamiento del déficit público mediante el incremento de la deuda pública (Edwards, 1989).

Esta misma visión de la acción del sector público predominaba en la mayoría de los países y la política económica contenía los mismos principios generales: acción del gobierno vía el gasto público en inversión como motor de la economía. Esta idea prevalecía en tanto se consolidara el ahorro -que se considera tradicionalmente la fuente de financiamiento natural de la inversión para incrementar el acervo de capital de una economía, que da origen a un crecimiento económico-, por lo cual, ante la insuficiencia de fondos de ahorro, era necesaria la intervención estatal en la economía vía inversión pública, considerando que una vez alcanzado el ahorro necesario, la inversión pública debía contraerse para evitar un efecto crowding out con la inversión privada tal que provocara efectos recesivos sobre el producto y la productividad de los factores, a consecuencia de la aglomeración de infraestructura generada por un exceso de inversión pública. Esto hace que la infraestructura económica se convierta en un insumo "libre" y por tanto no se tengan los efectos a escala previstos por el desperdicio de dicho insumo pues no se maximiza su utilización como insumo de la producción.

Sin embargo, el mal desempeño económico en los años ochenta del siglo pasado forzó, sobre todo a los países de América Latina, a cambiar su estrategia de ISI, con participación activa del Estado en la economía, a otra estrategia orientada hacia afuera o de liberalización, desregularización y privatización de amplios sectores económicos. ${ }^{8}$ La estrategia de reducción de la función del Estado en la economía ha ido acompañada, en países como México y Chile, por ejemplo, por la implantación simultánea de medidas de reducción del gasto público, y

\footnotetext{
${ }^{8}$ Al respecto, puede consultarse Fishlow (1990), quien ofrece una excelente revisión del cambio en la función del Estado en América Latina durante la década de los ochenta.
} 
en especial por la reducción de la inversión pública ${ }^{9}$ para asegurar, conforme la estrategia seguida, la eficiencia de largo plazo de la inversión privada generada por el proceso de privatización y liberalización.

Conforme a este nuevo modelo de crecimiento, la inversión pública deja de ser concebida como motor de crecimiento y esta función la retoma el ahorro (como la teoría tradicional del crecimiento económico lo propone), por lo cual hay un viraje radical en la política económica y en la función del Estado en el proceso de crecimiento económico, pasando a ser este último un promotor del ahorro mediante el impulso a las fuerzas del mercado a partir de la desregulación de los mercados, tanto del producto como de los factores, y de la privatización de las empresas estatales. La justificación económica de tales medidas se encuentra en los recursos limitados, internos y externos, disponibles por los gobiernos durante la década de los ochenta, pero también por los resultados ineficientes y las fallas generadas por la aglomeración de inversión pública localizada en sectores donde el sector privado es competitivo, provocando una sustitución de la inversión privada por la inversión pública.

No obstante los esfuerzos justificados por disminuir el aparato gubernamental creado por la activa inversión pública pasada, también se reconoce, por parte de los partidarios de la reducción estatal, que debe haber una participación mínima del Estado en los asuntos económicos ${ }^{10}$ para el funcionamiento óptimo del mercado, mediante el aprovisionamiento de la infraestructura económica y social necesaria para la actividad económica. Por tal motivo, la aplicación de severas medidas de ajuste económico, que se traducen en grandes recortes al gasto público y en especial al correspondiente a la inversión pública, conforme la experiencia lo muestra en países donde se han aplicado dichas medidas, han generado déficit de infraestructura económica: insuficiencia y malas condiciones del sistema carretero, deficientes sistemas de provisión de energía, escasez de puertos y aeropuertos, etcétera. También se han producido carencias en la infraestruc-

\footnotetext{
${ }^{9}$ Por ejemplo, la inversión pública de México pasó de un nivel de 328.42 mil millones de pesos en 1980 a 151.43 mil millones de pesos en 1993, a pesos de 2003, conforme las cifras de la Secretaría de Hacienda y Crédito Público (SHCP), lo cual, exceptuando los años de 1980 y 1981, durante los cuales se tenía una participación activa del Estado en la economía, se tradujo en un decrecimiento de $7.66 \%$ promedio anual de la inversión física realizada por el sector público consolidado en el periodo señalado.

${ }^{10}$ Sobre todo en la provisión de bienes públicos que, por su naturaleza o costo, no pueden ser producidos por el sector privado pero que son necesarios para la producción puesto que generan externalidades positivas o ayudan a minimizar las externalidades negativas provocadas por la actividad económica privada.
} 
tura social: sistemas de salud no universales e ineficientes, inefectividad del sistema educativo, entre otras. Ello provoca que se incrementen los costos de transacción y que sólo se invierta en los proyectos más rentables, en perjuicio de la producción potencial que se pudiera realizar al respecto. En consecuencia, si aceptamos que la inversión pública en infraestructura económica y social, como se ha reconocido en la teoría del crecimiento endógeno, generalmente complementa, en vez de desplazar, a la inversión privada, por lo cual su continua y constante negación puede afectar negativamente las posibles ganancias que se generen por los procesos de liberalización y privatización.

Por consiguiente, surge de nueva cuenta el debate sobre los efectos de la intervención estatal en la economía y, más específicamente, los efectos del gasto público en el crecimiento. Sin embargo, se reconoce que la actividad estatal puede, al menos indirectamente, incrementar el producto a partir de la interacción entre la inversión pública y la inversión privada. En este sentido, se debe tener en claro que la actividad gubernamental no sólo provee bienes públicos, elimine o bien regule las externalidades negativas, sino también puede proveer la infraestructura económica y social que facilita el crecimiento económico y mejora tanto la distribución de recursos como la productividad laboral mediante los gastos en salud y educación. Asimismo, puede subsidiar a industrias clave de exportación para mejorar la balanza comercial y acelerar el crecimiento económico, como sucedió en el pasado con los países asiáticos y recientemente sucede con los países denominados emergentes que conforman Brasil, Rusia, India y China (BRIC), los cuales en los años recientes han tenido un mayor dinamismo económico. Sin embargo, también se tiene que reconocer los posibles impactos negativos en el crecimiento económico generado por la distorsión que el sistema impositivo puede provocar en la actividad privada, además de los desincentivos y la posible ineficiencia en la provisión de los bienes públicos, incrementando los costos privados en la producción de bienes y servicios de una economía.

Dado lo anterior, es claro que también los determinantes de la inversión pública, como gastos productivos del gobierno, y no sólo los del ahorro privado, como convencionalmente se hace, ${ }^{11}$ se pueden situar como generadores de

\footnotetext{
${ }^{11}$ Por ejemplo, Ortiz (2007, cap. VIII), al analizar la política económica de México en los años recientes, encuentra que las políticas de fomento al ahorro como motor de crecimiento si bien han conseguido incrementar el ahorro total de la economía, han sido contraproducentes en tanto que han castigado la inversión, y en lugar de financiar la inversión han financiado al consumo público y privado, sin lograr los efectos positivos en el crecimiento económico. A igual conclusión llegan García-Alba y Soto (2004), quienes a partir de un análisis diferente señalan que no basta la existencia
} 
riqueza. En consecuencia, la eficacia de la inversión pública, como gasto público productivo, puede ser el ancla para impulsar el crecimiento económico cuando genere externalidades positivas que propicien el incremento de las oportunidades de inversión rentables. Bajo esta circunstancia, la inversión pública no será productiva ni generadora de riqueza si es canalizada como desperdicio a usos no rentables en el nivel macroeconómico, lo cual puede ser reflejado cuando el flujo de gasto que constituye la inversión pública se utiliza para financiar mayormente el gasto corriente inherente a la inversión que para lograr una mayor productividad de la inversión. Por lo tanto, la incapacidad de crecimiento de una economía radica en la ausencia de políticas y de un ambiente propicio para incrementar la productividad de la economía, la cual se da con la promoción de inversión, pública y privada y no en la generación de ahorro como lo señalan los teóricos ortodoxos.

\section{UN MODELO DE DOS SECTORES CON GASTO PÚBLICO GENERADOR DE RIQUEZA}

\section{Marco conceptual}

¿Por qué gran parte de las economías del mundo están sumergidas en la pobreza? ¿Por qué algunos países son ricos y otros pobres? ¿Cuál es la receta para superar la pobreza? ¿Existe una clave para el éxito? Estas preguntas fueron analizadas por vez primera en forma sistemática por Adam Smith en su libro seminal La riqueza de las naciones hace ya más de 200 años. A pesar de lo antiguo de la búsqueda por aclarar estas incógnitas, las preguntas planteadas todavía parecen estar vigentes y siguen intentando ser respondidas sin que se tenga una respuesta que satisfaga las expectativas de políticos y economistas.

La respuesta tradicionalmente aceptada, rescatada de Smith, se encuentra dentro de la teoría del crecimiento económico, en la cual es común considerar el ahorro como el principal determinante del crecimiento en función de que el primero es utilizado para adquirir trabajo y capital para, conforme el sistema económico prevaleciente, combinarlos de forma tal que se genere un proceso

del ahorro para financiar la inversión y generar crecimiento, sino que es importante el uso que se le dé a dicho ahorro, además de que muestran, para el caso de México, que la inversión es precisamente la causa del ahorro y no a la inversa, como se presupone dentro de la teoría neoclásica, debido a deficiencias estructurales, como la ausencia de políticas que fomenten la productividad a partir del impulso a la inversión, pública y privada. 
productivo de bienes o servicios, los cuales, en términos de valor, son superiores a los empleados originalmente, creándose de esta manera riqueza. Esta conclusión es producto de considerar al ahorro ex post igual a la inversión. Por ello se ha magnificado y justificado la importancia del ahorro en el diseño de las políticas para promover el crecimiento económico y generar la riqueza que permita un mayor bienestar a las familias de una economía. Sin embargo, esta preocupación razonable se ha llevado al extremo, sobre todo dentro de la bibliografía macroeconómica tradicional, al considerar el ahorro como el límite al crecimiento en tanto dicha economía no pueda generar el suficiente ahorro para financiar los proyectos rentables que permitan la producción de bienes y servicios. ${ }^{12} \mathrm{Pe}$ ro cabe preguntarse: ¿cómo puede generarse riqueza si lo que se considera como su fuente, la oferta de ahorro disponible, está deprimida, sobre todo cuando las economías han estado expuestas a crisis económicas constantes? ¿De dónde se podrá generar el incremento en el ingreso que dé por resultado un ahorro mayor, si existe una depauperación constante en los años recientes? ¿Quién puede ahorrar?

Teniendo en cuenta estas cuestiones, se intentará mostrar que partiendo de la consideración de que si un mayor crecimiento requiere una mayor acumulación de factores de producción o una mayor productividad de esos factores, entonces tanto el uno como el otro están estrechamente ligados a la inversión, por lo cual el ahorro no necesariamente es un prerrequisito para generar riqueza mediante la inversión, como se sugiere tradicionalmente. Es necesario, entonces, postular, en contrario sensu al enfoque tradicional del crecimiento económico, que la causalidad para la generación de riqueza expresada en un dinamismo económico se produce de la inversión al ahorro y no a la inversa. ${ }^{13}$

\footnotetext{
${ }^{12}$ Por ejemplo, Ortiz (2007) y García-Alba y Soto (2004) han examinado las consecuencias estructurales de la política económica aplicada en México en los años recientes planteada en los diversos Programas Nacionales de Financiamiento (Pronafide), los cuales han tenido como eje fundamental promover el ahorro interno como condición sine qua non para generar crecimiento económico. Sin embargo, la evidencia empírica mostrada por ambos estudios observa que las políticas de promoción de ahorro ni generan ahorro ni lo promueven, sino lo contrario: el ahorro total se mantiene en niveles constantes y el ahorro interno y el externo en lugar de emplearse en los proyectos rentables de inversión se utilizan para financiar el consumo público y privado, aunque este último en menor medida. Asimismo, se pervierten las políticas de fomento al ahorro, al tener como ancla la tasa de interés que fomenta un gasto especulativo que no genera crecimiento y provoca en cambio desequilibrios en el sistema financiero.

${ }^{13}$ Esta postura económica es reciente y se encuentra dentro del campo de la teoría del crecimiento económico endógeno iniciada por el trabajo seminal de Romer (1986) y continuada por Lucas (1988), la cual consiste en afirmar que el crecimiento económico es endógeno y no exógeno,
} 
Sin embargo, es importante reconocer que la inversión privada tiene restricciones de financiamiento, por lo cual los flujos de capital están restringidos y ello no permite a un agente económico gastar en la adquisición de factores productivos que permitan la acumulación de capital físico y humano o en el mejoramiento de su acervo de capital para incrementar la productividad de sus factores. Si esto ocurre en una economía con dinamismo económico, entonces en una economía pequeña la restricción de inversión privada y de flujos de capital tampoco posibilita al sector privado ser quien aporte los recursos para la inversión, por lo que para llevar a cabo la acumulación de capital requerida y generar las condiciones óptimas para el crecimiento económico generador de riqueza es necesario la acción de otro actor: el sector público. Esto implica que ante la imposibilidad del sector privado para aportar los recursos mediante el ahorro para la inversión, el sector público debe proveer dichos recursos para que el mecanismo funcione quedando, por tanto, la causalidad como sigue: si el sector público genera un gasto productivo, ${ }^{14}$ en tanto mejora las condiciones para la inversión, mediante la creación o expansión de la infraestructura física o por medio del incremento de la productividad a partir del gasto en la formación de capital humano (avance de las condiciones de salud, educación, alimentación, entre otras), puede también ocasionar una fuente de ingresos para los agentes económicos y factores que lo reciben, con lo cual una parte la destinan para su consumo presente y otra para su consumo futuro, con lo que se genera ahorro privado. Dicho ahorro puede ser utilizado como fuente de financiamiento para la inversión privada, la cual al realizarse genera un incremento en la utilización de los factores productivos provocando un incremento del producto que se expresa en riqueza. Esta riqueza está dada por un incremento en el ingreso percibido por todos los agentes económicos en el proceso de la producción, lo que conduce a otro incremento del ahorro conjuntamente con mayores ingresos tributarios pagados por los agentes privados y percibidos por el sector público, para continuar así con el proceso de nueva cuenta.

Por tanto, más que la restricción de ahorro, la restricción al crecimiento que impera en una economía es su incapacidad para generar proyectos rentables

como se presuponía, por lo que si se efectuaran inversiones en aquellos factores que mejoran la productividad, como nuevos inventos, procesos, creación de capital humano, entre otros, el crecimiento estaría garantizado y se generaría por sí mismo. Es decir, la eficiencia, la innovación y el cambio tecnológico inducido son los verdaderos determinantes de una mayor productividad de la inversión que genera crecimiento económico.

${ }^{14}$ Gasto que en un sentido más amplio y reconocido puede encuadrarse como inversión pública. 
de inversión. En consecuencia, el papel que tiene el gasto público productivo es el de generar las condiciones físicas y humanas que eliminen dicha restricción. Si el gasto público productivo genera las condiciones para llevar a cabo una cantidad mayor de proyectos productivos rentables a cargo del sector privado, éstos tenderán a encontrar por sí mismos los medios de financiamiento (interno o externo), generando recursos suficientes para pagarse solos como requisito fundamental de su rentabilidad, provocando así un incremento en la riqueza neta de una economía. Por tanto, la incapacidad de crecimiento de la economía o bien la incapacidad de generar riqueza, radica en la ausencia de políticas públicas y de un ambiente institucional responsables de la economía que propicien el aumento de la productividad de los factores en forma individual o de la economía en su conjunto, los cuales generarán oportunidades de inversión rentables en procesos productivos con valor y no, en cambio, deficiencias estructurales, como ahorro insuficiente y su nula generación, al contrario de lo previsto por la teoría ortodoxa.

\section{El modelo}

El modelo desarrollado a continuación tiene como finalidad subsanar la deficiencia teórica respecto a la relación existente, pero poco reconocida, entre el crecimiento logrado por economías con gran dinamismo y las políticas y estrategias que implantaron o que pueden implantar los gobiernos para sostener dicho crecimiento o generarlo. Para ello, se tiene que partir de que dadas las condiciones cambiantes del sistema económico capitalista, en nuestros días los determinantes de la inversión y no los del ahorro son quienes generan la riqueza expresada por trayectorias de crecimiento económico sostenido. En consecuencia, el crecimiento económico y la inversión dependen no sólo de la capacidad de generar ahorro, como se plantea tradicionalmente, sino de las políticas públicas de desarrollo que se implanten para crear las condiciones propicias para la inversión productiva, pública o privada. Por tanto, la premisa fundamental de lo anterior es que la acumulación del capital productivo en sí mismo (ahorro) no es el factor determinante para explicar las diferencias en el crecimiento económico de las naciones.

Bajo este matiz, se parte de una economía compuesta por dos sectores: el sector público o gubernamental y el sector privado o no gubernamental, donde el primero cumple con su función cuando tiene identificados determinados proyectos para infraestructura física o social tales que al destinárseles parte del gasto 
público ${ }^{15}$ puedan generar un acervo de capital público entendido como un conglomerado disponible de infraestructura económica y social proveniente de los flujos de inversión pública y gasto social respectivamente, que puede ser utilizado a bajo $\operatorname{costo}^{16}$ por los agentes económicos del sector no gubernamental para lograr mayor productividad de su inversión y conformar economías a escala y aumentar así el potencial máximo de una economía.

Respecto al financiamiento del gasto público productivo, éste se rige según la restricción presupuestal del sector público, es decir, el conglomerado de la infraestructura pública o acervo de capital público, junto con el consumo público, proviene de los impuestos actuales, por lo cual el balance público se supone en equilibrio.

Por último, como se quiere demostrar que el gasto público productivo tiene efectos en la formación de capital privado, en la productividad de los factores o bien sobre ambos, entonces también se estaría demostrando que dicho gasto influirá en los inversionistas privados respecto a sus expectativas de ventas y ganancias futuras y no sólo sobre la demanda agregada de bienes y servicios producidos por el sector privado, por lo que influiría directamente en el crecimiento económico y, por ende, en la generación propia de riqueza sin que se produzcan desplazamientos entre la inversión pública y la privada. Sin embargo, para ello es necesario introducir el acervo de capital público como un factor más del proceso productivo, en tanto que el gasto público productivo generador del capital público debe ser tratado como acervo y no como flujo para ser comparable dentro de cualquier función de producción.

Dadas las anteriores consideraciones, el análisis del modelo plantea una economía descentralizada en la cual hay ausencia de dinero con empresas y

\footnotetext{
${ }^{15}$ Este gasto público lo podemos clasificar en gasto público productivo o improductivo. El gasto público productivo puede ser en creación o mantenimiento de infraestructura física (inversión pública) o en formación y mejoramiento del capital humano o infraestructura social (gasto social) y será productivo en tanto contribuya a incrementar las oportunidades de inversión, haciéndolas más rentables. Mientras, el gasto público no productivo es el consumo público (o gasto corriente) que no contribuye a la producción (Hernández, 2009).

${ }^{16}$ El precio del capital público viene determinado por su costo de producción, que si bien es alto de manera individual, es bajo colectivamente al diseminarse entre toda la carga impositiva de los contribuyentes; por tanto, el capital público no puede considerarse un bien libre como tal. Así, si el acervo de capital público tiene un costo tal que por un lado permita su accesibilidad y por el otro se evite su congestión provocada por su demanda, entonces el capital público utilizado puede generar externalidades positivas tales que el proceso productivo muestre rendimientos crecientes, lo cual implica un incremento de la productividad derivado del uso del acervo de capital público disponible en una economía en un tiempo determinado.
} 
agentes idénticos, de manera que los consumidores y productores se consolidan y el sector no gubernamental puede ser modelado como un trabajador-empresario representativo. ${ }^{17} \mathrm{Si}$ además consideramos que el capital público es un stock de infraestructura económica y social provisto por el sector gubernamental mediante un gasto productivo o gasto en inversión, esto permite crear un acervo de capital que se encuentra disponible para ser utilizado por el sector no gubernamental en los procesos productivos a cargo de éste, pues es no exclusivo y no rival frente al capital privado, pero con un precio; entonces podemos partir de la consideración de la siguiente función producción, que muestra la relación funcional entre los dos sectores y los insumos que se disponen:

$$
Y_{t}=F\left[A K_{p t}^{\alpha}, K_{g t}^{\beta}, L_{t}^{\gamma} ; G_{t}\right] \quad \alpha, \beta, \gamma,>0,
$$

donde $Y_{t}$ es el producto agregado producido por los insumos provistos por los dos sectores de la economía; $F($ ) es una función producción general dependiente del gasto público $(G)$, y de los insumos productivos: trabajo $(L)$, y capital público y privado $\left(K_{g}\right.$ y $\left.K_{p}\right)$; $A$ es un índice de productividad de la economía que refleja la relación tecnológica prevaleciente en un momento dado, en tanto los coeficientes $\alpha, \beta$ y $\gamma$ son las elasticidades de los insumos respecto al producto.

Siguiendo a Barro (1990), se supone que el gobierno financia sus flujos de gastos brutos por medio de una tasa impositiva al ingreso $(\tau)$, de manera que:

$$
G_{t}=\tau Y_{t}
$$

Esta restricción presupuestal describe el flujo del gasto público productivo y/o improductivo, cuyo financiamiento proviene de los ingresos obtenidos vía una tasa impositiva uniforme aplicada al producto, motivo por el cual el precio del capital público individual para el sector no gubernamental que desee utilizarlo es igual a la proporcionalidad de los impuestos que paga. Ello implica, por tanto, que el gasto público productivo no constituye un gasto en consumo, permitiendo entonces que dicho gasto pueda tratarse como inversión pública y, por tanto, susceptible de ser acumulable, constituyendo un acervo de capital público. Esto resulta significativo para justificar su inclusión dentro de la función produc-

\footnotetext{
${ }^{17}$ Esto implica una población constante bajo el supuesto de que la población, $L$, crece a una tasa constante y exógena, $n$, tal que $\frac{\dot{L}}{L}=n \geq 0$, por lo que se tiene una economía real con población constante.
} 
ción como parte del acervo agregado de capital de la economía adoptando un desempeño complementario y no sustitutivo respecto al capital privado en los procesos productivos iniciados por el sector no gubernamental.

Así, si se considera que existe un acervo inicial de infraestructura pública, la cual, como ocurre también con el capital privado, presenta un proceso de desgaste (depreciación) por su uso a lo largo del tiempo, entonces la acumulación de capital público puede expresarse como:

$$
\dot{K}_{G}=I_{G}-\delta_{G} K_{G}
$$

Siendo $\delta_{G}$ la depreciación del capital público e $I_{G}=\theta G$ la inversión pública bruta que es equivalente al gasto público productivo, siendo $\theta$ la parte proporcional del gasto público que no se destina al consumo público y que es financiada vía impuestos directos uniformes a los ingresos de los agentes mediante la tasa $\tau_{\theta}$, a efecto de mantener el equilibrio presupuestal del sector público, por lo cual la parte del producto generado que se destina a la inversión pública es:

$$
I_{G}=\tau_{\theta} Y
$$

Lo anterior significa que el gasto público productivo, al ser equivalente a la inversión pública, provoca adiciones al acervo total de capital de la economía por medio de la formación de capital público, $K_{g}$, que es equivalente al conglomerado de infraestructura económica y social disponible para todos los agentes de la economía en cualquier momento y cuyo uso permite incrementar la productividad, mejorando las condiciones para obtener mayores proyectos de inversión rentables, con la misma cantidad de ahorro disponible, y generando un producto mayor. Además, las expresiones (3) y (3a) vinculan la acumulación del capital público generado por el flujo del gasto público productivo con las decisiones de gasto y tributación de los agentes, lo cual significa que el gobierno puede elegir una política pública que asuma las reglas de decisión del agente privado haciendo endógena a su vez la inversión pública en infraestructura. Es decir, puede adoptar la forma de un planeador central en el proceso de maximización de un agente representativo de una economía dada sin que se provoquen efectos crowding out sobre la inversión.

Esto último adquiere relevancia, pues al considerar la función producción dada por la expresión (2), tenemos que el capital público al combinarse con por lo menos el factor trabajo, puede ocasionar un aumento directo del producto, 
independientemente de que éste sea sustitutivo o complementario (esto es: $\left.\frac{\partial Y}{\partial K_{G}}=\beta\left(Y / K_{G}\right)>0\right)$, pero también de manera indirecta, si el capital público es complementario al capital privado, teniendo un efecto positivo sobre la productividad marginal del capital privado y sobre el trabajo (esto es: $\frac{\partial Y}{\partial K_{P} \partial K_{G}}>0 \mathrm{y}$ $\left.\frac{\partial Y}{\partial L} \frac{\partial K_{G}}{\text { a }}>0\right)$. La causa de estos efectos se encuentra en que la inclusión del capital público como un insumo de la función producción puede elevar los rendimientos a escala siempre y cuando se asuma que prevalece una utilización eficiente del capital público.

Lo anterior supone entonces, que el capital público afecta la eficiencia del trabajo o del capital privado de manera proporcional en sentido positivo o negativo, por lo cual tenemos que dichos efectos los podemos expresar como $\phi_{i}=\phi_{i}(G)$ para $i=L$ o $K$. Entonces, la función producción (2) se transforma en:

$$
Y_{t}=F\left[\phi_{K} K_{t}^{\alpha}, \phi_{L} L_{t}^{\beta}, \phi G_{t}\right]
$$

Así, el gasto público productivo empleado para mejorar la eficiencia de los factores de la producción generará efectos indirectos y directos sobre los otros factores productivos: capital público y privado $(K)$ y trabajo $(L)$. Diferenciando totalmente (5) respecto a cambios en los insumos, e implícitamente respecto al gasto público $(G)$, y dividiendo el diferencial entre $Y$ para expresar la tasa de crecimiento del producto, se obtiene:

$$
\frac{d Y}{Y} \equiv \frac{\dot{Y}}{Y} \equiv y=\alpha(G) \frac{d K}{Y}+\beta(G) \frac{d L}{Y}+\theta(G)\left(\frac{\dot{G}}{Y}\right)
$$

donde $\left(\frac{\dot{G}}{Y}\right) \equiv d\left(\frac{G}{Y}\right)$ es el cambio del gasto público como proporción del producto interno bruto (PIB). Ahora bien, considerando que el flujo de inversión, $I$ (pública y privada) provocada por un incremento del gasto público productivo representa el incremento en el capital total de la economía $(d K=I)$, entonces $(5 a)$ se transforma en:

$$
\frac{d Y}{Y} \equiv \frac{\dot{Y}}{Y} \equiv y=\alpha\left(\frac{I}{Y}\right)+\beta \frac{d L}{Y}+\theta d\left(\frac{G}{Y}\right) .
$$

En consecuencia, la tasa de crecimiento económico de una economía con gasto público productivo depende de las productividades marginales de los factores $(\alpha$ y $\beta)$ y de la elasticidad ponderada $(\theta)$ de un cambio en la participación del gasto público. Por tanto, si la participación del gasto público productivo 
dentro del gasto público total es cercana a 1, esto provocará una mejora en la eficiencia de los factores que se reflejará en el incremento de sus productividades y, por tanto, redundará en un mayor crecimiento económico. Así, el determinante endógeno del crecimiento es el gasto público productivo, el cual tiende a mejorar la eficiencia de los factores afectando su productividad de manera positiva. Sin embargo, si la participación del gasto público improductivo dentro del gasto total es mayor, el efecto sobre el producto tenderá a diluirse, por lo cual no existen afectaciones a la eficiencia del producto que permitan mejorar la productividad de los factores. Así, la inversión privada y el cambio en la participación del gasto público productivo son las dos variables endógenas que afectan la tasa de crecimiento de una economía con al menos dos sectores: el público y el privado.

Producto de lo anterior, se tiene que aun cuando se acepte la igualdad ahorro/inversión, la conclusión anterior prevalece. Es decir, el ahorro no es una restricción insustituible para generar riqueza, sino que a pesar de que en una economía la restricción de ahorro prevalezca, se puede generar crecimiento con otras variables endógenas, como el gasto público productivo. Para mostrar lo anterior, considérese la igualdad/ahorro inversión:

$$
(I / Y)_{t}=S
$$

donde el ahorro $(S)$, en una economía cerrada, es una función que depende de la tasa de crecimiento del producto, $d Y / Y$ y del nivel del ingreso real $\left(Y_{R t}\right)$, considerando que el ahorro es el ingreso que no se gasta en el presente sino en el futuro, de tal forma que se obtiene:

$$
S_{t}=s\left(d Y / Y, Y_{R t}\right) \text {. }
$$

Mientras, la inversión, como proporción del producto, para el año $t$ es una función de la tasa de ahorro; por tanto, la inversión es especificada en la forma:

$$
\left(\frac{I}{Y}\right)_{t}=h\left(S_{t}\right)
$$

Sustituyendo (6) en (7), obtenemos:

$$
\left(\frac{I}{Y}\right)_{t}=h\left(d Y / Y, Y_{R t}\right)
$$

lo que significa que la inversión, como proporción del producto, está en función de la tasa de crecimiento del producto $(d Y / Y)$ y del nivel del ingreso real $\left(Y_{R t}\right)$. 
Por tanto, se verifica nuestra hipótesis inicial de que, ante restricciones de ahorro para generar riqueza, no es necesario impulsar políticas estructurales de generación de ahorro, sino que basta con que el sector público tenga políticas de gasto público productivo capaces de fomentar la eficiencia de los factores productivos para incrementar directa o indirectamente el producto y, en consecuencia, crear riqueza, que se reflejará en un crecimiento económico, sin que se tengan efectos perniciosos sobre las finanzas públicas o sobre la inversión privada. Asimismo, en tanto que el gasto público productivo está financiado por la vía impositiva y la acción sobre la inversión privada es de complementariedad y no de sustitutibilidad, se garantizan efectos a escala que permiten la obtención de rendimientos crecientes, generando a su vez un incremento del ahorro para tener mayores fuentes de financiamiento que pudiese ser destinado a la inversión privada, entrando así en un círculo virtuoso. Esta situación difiere de los modelos de tres brechas (ahorro, divisas y fiscal), los cuales señalan que para generar crecimiento económico es necesario romper con la brecha fiscal a partir de la generación de superávit fiscal vía señoreaje o austeridad fiscal, priorizando en la inversión pública en cuanto al uso de los recursos disponibles, captando ahorro privado adicional (Bacha, 1990).

\section{LA EXPERIENCIA MEXICANA (1980-2009)}

\section{Los datos}

El comportamiento económico de México en los pasados 30 años ha estado marcado por la magnitud y las consecuencias de las crisis económicas, imposibilitando la generación de ciclos económicos regulares. Por esta razón, como se muestra en el cuadro 1, la tasa promedio anual de crecimiento de la economía mexicana durante el lapso considerado ha sido de $2.56 \%,{ }^{18}$ siendo el periodo de 1990 a 1999 el que ha presentado una mayor tasa de crecimiento promedio anual de la economía (3.38\%), en contraste con la última década (2000-2009), que reportó la tasa de crecimiento promedio anual más baja (1.94\%).

\footnotetext{
${ }^{18}$ Sin embargo, si omitimos los años de 1980 y 1981 del periodo considerado, años en los cuales el producto interno bruto (PIB) creció a tasas de 9.48 y $8.52 \%$, respectivamente, entonces la tasa de crecimiento promedio anual fue de $2.10 \%$ para el periodo $1982-2009$, siendo los años de 1996 a 2000 el periodo que registra el mejor comportamiento económico, con una tasa anual de crecimiento promedio de 5.46 por ciento.
} 


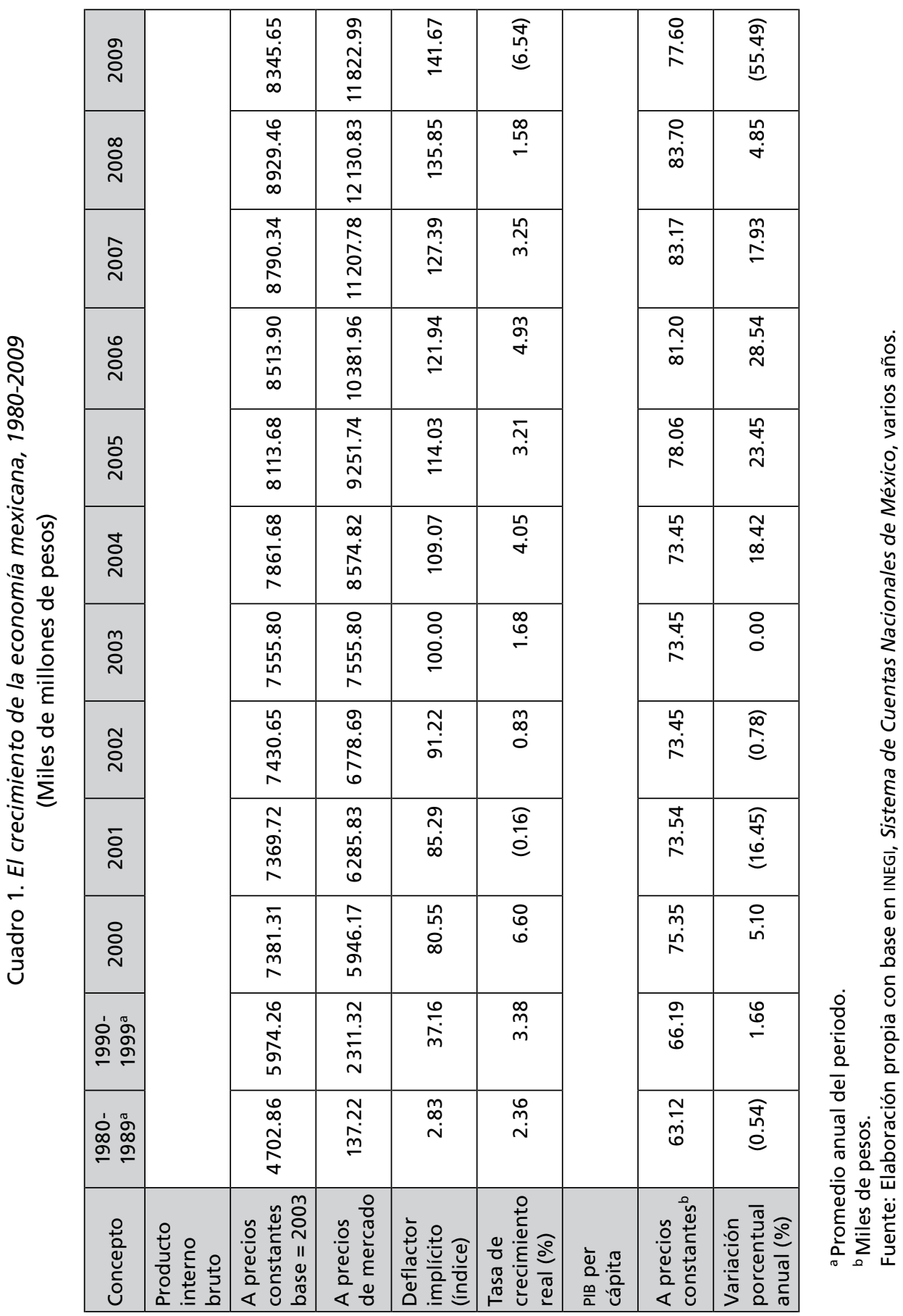


En consideración de lo anterior, el consenso de los diversos análisis que se han llevado a cabo señala que hasta antes de la crisis de 1994 los determinantes principales han estado vinculados a las caídas abruptas en el precio del petróleo, ocasionando crisis fiscales, junto con corridas masivas de flujos de capital, devaluaciones graves y elevadas tasas de inflación, con la consecuente caída de los términos de intercambio y el deterioro de la balanza de pagos. En cambio, la crisis de 1994 tiene que ver con el manejo no óptimo del financiamiento externo que, sumado con la inestabilidad política y el uso indiscriminado de los instrumentos financieros para financiar el consumo personal, el resultado fue un deterioro significativo de la balanza de pagos que culminó en la adopción del régimen de libre flotación tras una fuerte devaluación del tipo de cambio. Esta crisis de 1994, inauguró el proceso de inestabilidad financiera en México provocada por la volatilidad de los instrumentos financieros generando, a su vez, graves contracciones del sector manufacturero debido a la aversión al riesgo mostrada por los inversionistas en el financiamiento de los proyectos productivos de alto impacto. ${ }^{19}$

Resumiendo, la combinación de choques exógenos que afectan la productividad del país y los errores de política económica son las causas reconocidas de las crisis económicas presentadas en la economía mexicana hasta 1994. A partir de este año, por lo contrario, se ha dado un manejo consistente de la política económica, pero no exento de errores de regulación, sobre todo los ocurridos en los mercados financieros, los cuales son las causas principales de la nueva volatilidad de la economía.

Sin embargo, hay que considerar que la situación anterior ha generado una dinámica de represión de la capacidad productiva del país, donde la función del gobierno en la economía mexicana pasó de promotor del crecimiento económico, por medio de la inversión pública, a benefactor de procesos de liberalización económica, reflejándose así un cambio estructural en el diseño macroeconómico de las variables de política económica ${ }^{20}$ sobre todo por la cuestión de obtener

\footnotetext{
${ }^{19} \mathrm{Al}$ respecto, puede señalarse como indicador que la inversión extranjera directa, como proporción de la inversión extranjera total, ha ido recomponiéndose al pasar de cerca de $70 \%$, promedio anual, en el periodo 1980 a 1990 a $15.42 \%$ en el último trimestre de 2009 , lo cual se explica por su sustitución por la inversión de cartera, conforme a los datos presentados en www.banxico.org.mx/ politica-monetaria-e-inflacion/estadisticas/otros-indicadores/balanza-pagos.html.

${ }^{20}$ Véase por ejemplo el cuadro 4, el cual muestra que la inversión física como proporción del PIB decreció de un promedio anual de $5.42 \%$ en el periodo $1980-1989$ a $2.88 \%$ en $1990-1999$ y continuó en descenso hasta llegar a $2.82 \%$ durante el periodo 2000-2009, considerando que aun durante la mayor parte de la década de los ochenta, el gasto público no tuvo una contracción sino una recomposición del mismo como producto de la crisis económica de 1982, al reducirse la participación
} 
recursos fiscales para cumplir con los compromisos de la deuda externa por medio de los ajustes en el gasto público, con el consiguiente costo de dejar de promover la demanda y capacidad productiva internas y, por lo tanto, de promover el crecimiento económico a ritmos de $6 \%$ promedio anual de finales de los años setenta y principios de los ochenta del siglo pasado. Pero, a pesar de ello, las participaciones del gasto público total en el producto interno bruto de la economía mexicana pasaron de un promedio anual de $36.58 \%$ en la década de los ochenta del siglo pasado a un promedio anual respecto al PIB de $21.93 \%$ en la década de los noventa y de $22.26 \%$ en la primera década del siglo XXI (véase cuadros 2-4).

En este sentido, era de esperarse que la tasa de crecimiento promedio anual del gasto presupuestario durante la década de los ochenta no decreciera, como realmente sucedió ( $7.54 \%$ el promedio anual de crecimiento del gasto público en este periodo), aunque este aumento se explica por el incremento del gasto destinado a cubrir el servicio de la deuda externa y no por el gasto de capital que tuviera efectos en el aparato productivo de la economía mexicana. ${ }^{21}$ Así, en el periodo de 1985 a 1991 el gobierno llevó a cabo políticas de estabilización económica abandonando su estrategia de industrialización por sustitución de importaciones e implantando, a partir de ello, un programa de liberalización y privatización que culminó con la apertura comercial de la economía mexicana que se consolidó con la entrada en vigor del Tratado de Libre Comercio de América del Norte en 1994, con un retraimiento general del sector público en las actividades productivas y un cambio en las herramientas de la política fiscal para la promoción del crecimiento consistente en la menor utilización in extenso del gasto público en actividades económicas productivas y de la formación directa de capital, por un impulso a iniciativas de promoción de la formación del capital privado tales como créditos generales y específicos para la industria manufacturera exportadora, créditos fiscales de empleo y reducción de las tasas impositivas para los corporativos.

del gasto programable (gasto corriente y de capital) e incrementarse la participación del gasto no programable (intereses, amortizaciones y participaciones de deuda pública), llegando el primero a constituir la mitad del segundo, por lo cual los efectos del gasto público en la economía fueron no productivos. Sobre los efectos de la composición del gasto público en la actividad económica véase Hernández (2009).

${ }^{21}$ Basta hacer notar que el promedio anual de la tasa de crecimiento del gasto de capital en el periodo 1980-1989 fue negativo en $0.92 \%$. (véase cuadro 3.) 


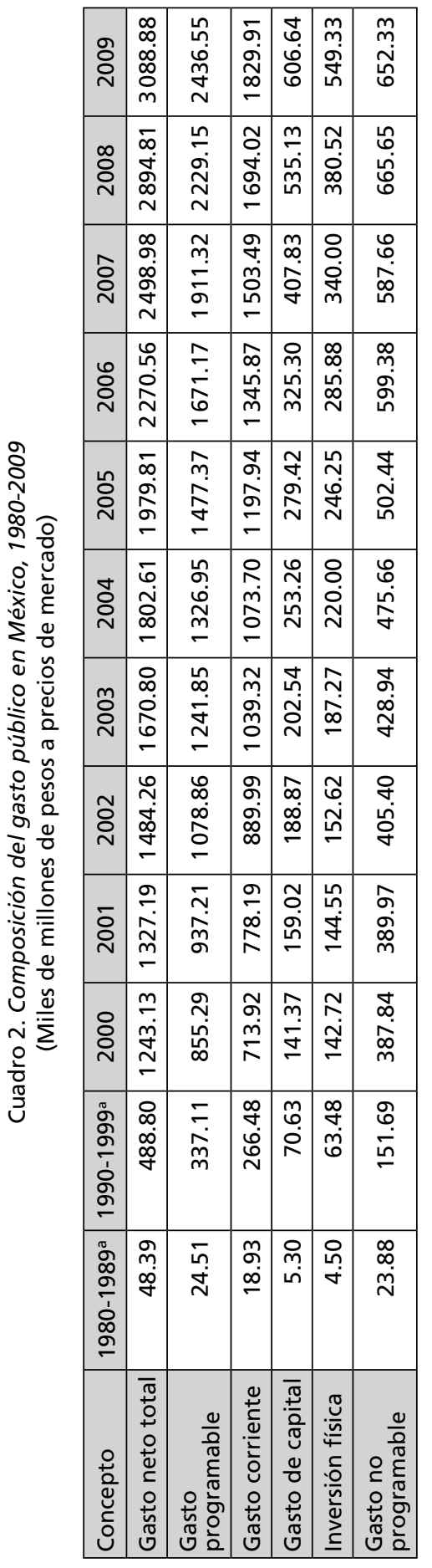

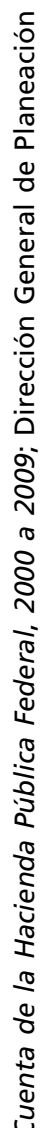

ญे

\begin{tabular}{|c|c|c|c|c|c|c|}
\hline ¿্ & $\stackrel{\sim}{n}$ & $\begin{array}{l}\stackrel{\infty}{\infty} \\
\sim\end{array}$ & $\begin{array}{l}\widetilde{D} \\
\infty\end{array}$ & $\underset{\infty}{\bar{N}}$ & $\begin{array}{l}\mathbb{Z} \\
\infty \\
m\end{array}$ & $\begin{array}{l}\text { ㅇ } \\
\text { d }\end{array}$ \\
\hline 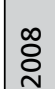 & $\underset{\infty}{\widetilde{\infty}}$ & $\begin{array}{l}\text { m. } \\
\sigma\end{array}$ & $\begin{array}{l}\hat{\sigma} \\
\stackrel{\sim}{ }\end{array}$ & $\begin{array}{l}\text { ठ } \\
\text { ்ָ }\end{array}$ & $\begin{array}{l} \\
\dot{r}\end{array}$ & $\begin{array}{l}\hat{N} \\
\stackrel{n}{n}\end{array}$ \\
\hline
\end{tabular}

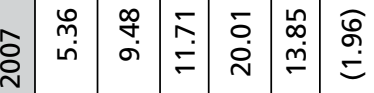

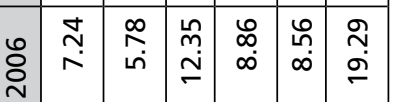

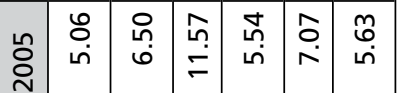

กิ

ơ

离

¿

온 원

ลำ

ฟั

ปั.

$\frac{\mathrm{d}}{\mathrm{d}}$

ธิ ปัป

วิำ

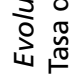

ì

ธ่

ฝั รั

ㄷํㅇ 음

은 응 ํำ

응응

흥 등

중

은 는 혼

过

은 눈 을

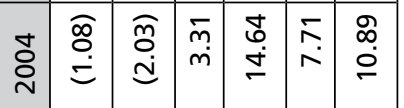

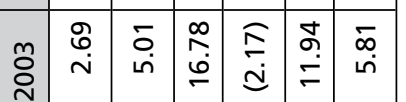

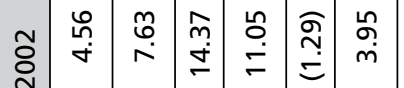

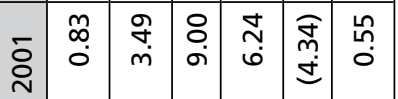

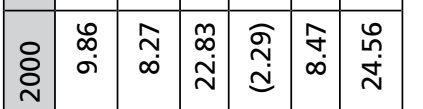

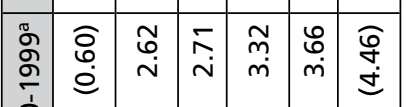

ㅇํํ

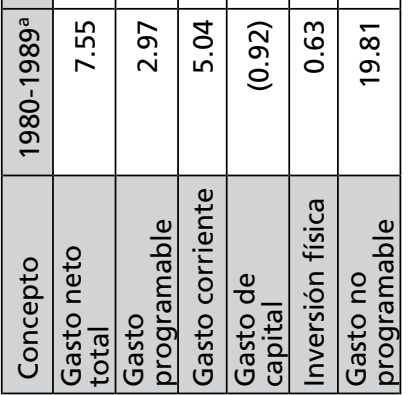

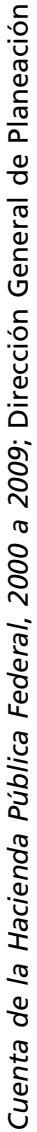

宅

๕⿺

๓ ริ

ㅇำ

ㄷํㅇ 용

으 응 ํำ

๕ั

ฮั ㄷํㅇ

药

\%

응 흔 논

है

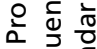


Asimismo, como parte del programa de austeridad fiscal introducido en 1986 con el fin de estabilizar la economía, las autoridades gubernamentales redujeron el gasto de capital, afectando con ello la inversión física del sector público, sobre todo en el periodo 1990-1999, pues una vez concluido el proceso de renegociación de la deuda de fines de la década de los ochenta, el gasto no programable (destinado al servicio de la deuda) disminuyó considerablemente hasta alcanzar una contracción del gasto público total de $0.60 \%$ promedio anual. Sin embargo, dado el proceso de cambio estructural ocurrido en la composición del gasto público durante la década de los ochenta, la inversión pública federal disminuyó su participación en la economía mexicana al pasar de 5.42\% del PIB en estos años a $2.88 \%$ en la década siguiente y a $2.82 \%$ en la última década, ${ }^{22}$ aunque en el año 2009 alcanzó una participación de $4.65 \%$, con una tasa de crecimiento para dicho año de $38.44 \%$. Esto último como producto de las medidas para fomentar la actividad económica decaída por la crisis financiera internacional de 2008, medidas consistentes, principalmente, en destinar recursos al fomento de infraestructura eliminando, por ejemplo, los esquemas de los proyectos de gasto diferido de largo plazo (Pidiregas) utilizados para financiar la obra pública de Pemex y CFE, y destinar los recursos presupuestales liberados al ejercicio directo de esta entidad pública.

Sin embargo, contrario a lo esperado con la implantación de las nuevas herramientas de política fiscal, la participación de la inversión del sector privado como proporción del PIB ha ido decreciendo durante el periodo analizado, pues de tener una participación de $25.73 \%$ en 1980 , descendió a un promedio anual de $19.62 \%$ en la década de los ochenta, $17.85 \%$ en la década de los noventa del siglo pasado hasta llegar a $20.09 \%$ en el periodo $2000-2009$, lo cual ha sido congruente con la disminución de la inversión extranjera directa, en tanto que las necesidades de financiamiento de la inversión privada en la formación bruta de capital fijo han disminuido, por lo cual el ahorro externo se ha redirigido a la inversión de cartera, explicándose así el dinamismo decreciente del mercado interno que ha propiciado el bajo ritmo de crecimiento de la economía mexicana, cuyo repunte constituye el objetivo central de los últimos años.

${ }^{22}$ Este cambio estructural consistió en la disminución drástica y directa de la participación del sector público en la economía mediante los procesos de desincorporación y privatización de las empresas públicas iniciadas en el sexenio de Miguel de la Madrid, intensificadas con Carlos Salinas de Gortari, terminadas con Ernesto Zedillo (con la venta de Ferronales) y rematadas recientemente con la extinción de Luz y Fuerza del Centro con Felipe Calderón en octubre de 2009, a tal grado que sólo existen dos entidades con acción directa en la economía: Petróleos Mexicanos (Pemex) y Comisión Federal de Electricidad (CFE). 
Gráfica 1. Inversion pública y privada como proporción del PIB (Porcentaje)

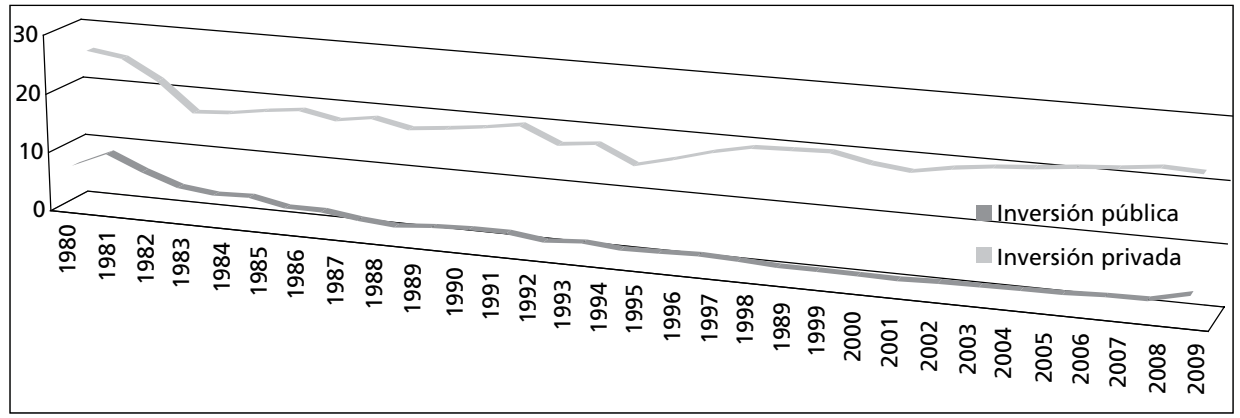

Gráfica 2. Tasas de crecimiento a precios constantes (Porcentaje)

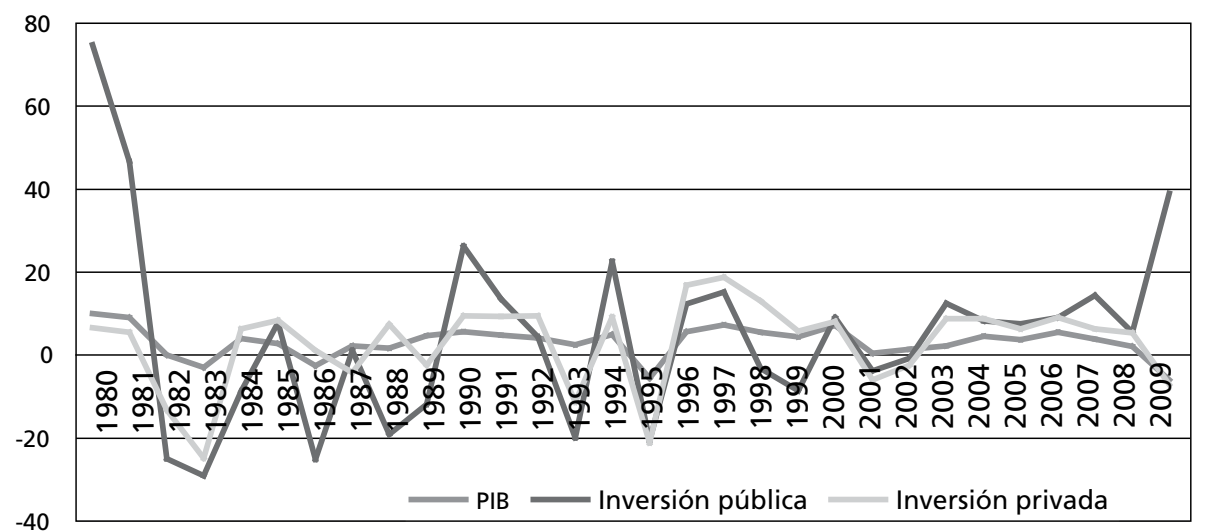

\section{Estimación del modelo y resultados generales}

Un tema importante de análisis de las finanzas públicas de la economía mexicana es el de los efectos de la inversión pública sobre la tasa de crecimiento del producto. Por un lado, la tasa media de crecimiento anual del PIB real a precios de 2003 del periodo 1980-1999 de 2.87\%, es superior a la presentada en la última década: $1.94 \%$. Por el otro lado, el gasto público ejercido por el sector público tuvo un ritmo de crecimiento alto durante los años previos al periodo de ajuste económico implantado en 1985: la tasa media anual de crecimiento real del gasto programable ejercido por el sector público fue alrededor de $30 \%$, con una participación respecto al PIB apenas superior a $20 \%$, porcentajes elevados en compa- 
ración con los prevalecientes a partir de 1983, cuyas medias oscilan alrededor de 4 y $15 \%$, respectivamente. Por tanto, puede pensarse que un elemento que pudo haber contribuido a la reducción del ritmo de crecimiento de la economía mexicana durante los pasados 25 años ha sido la recomposición del gasto público utilizado en actividades no productivas, conforme se muestra en el cuadro 4.

Cuadro 4. Participaciones del gasto público en México, 1980-2009

(Estructura porcentual)

\begin{tabular}{|c|c|c|c|c|c|c|c|c|c|c|c|c|}
\hline Concepto & $\begin{array}{l}1980- \\
1989^{a}\end{array}$ & $\begin{array}{l}1990- \\
1999^{a}\end{array}$ & 2000 & 2001 & 2002 & 2003 & 2004 & 2005 & 2006 & 2007 & 2008 & 2009 \\
\hline \multicolumn{13}{|c|}{ Participaciones respecto al producto interno bruto } \\
\hline $\begin{array}{l}\text { Relación gasto } \\
\text { total / PIB }\end{array}$ & 36.58 & 21.93 & 20.91 & 21.11 & 21.90 & 22.11 & 21.02 & 21.40 & 21.87 & 22.30 & 23.86 & 26.13 \\
\hline $\begin{array}{l}\text { Gasto programa- } \\
\text { ble / PIB }\end{array}$ & 21.18 & 14.79 & 14.38 & 14.91 & 15.92 & 16.44 & 15.47 & 15.97 & 16.10 & 17.05 & 18.38 & 20.61 \\
\hline $\begin{array}{l}\text { Gasto corriente/ } \\
\text { PIB }\end{array}$ & 15.04 & 11.57 & 12.01 & 12.38 & 13.13 & 13.76 & 12.52 & 12.95 & 12.96 & 13.41 & 13.96 & 15.48 \\
\hline $\begin{array}{l}\text { Gasto de capital/ } \\
\text { PIB }\end{array}$ & 6.04 & 3.23 & 2.38 & 2.53 & 2.79 & 2.68 & 2.95 & 3.02 & 3.13 & 3.64 & 4.41 & 5.13 \\
\hline $\begin{array}{l}\text { Inversión física/ } \\
\text { PIB }\end{array}$ & 5.42 & 2.88 & 2.40 & 2.30 & 2.25 & 2.48 & 2.57 & 2.66 & 2.75 & 3.03 & 3.14 & 4.65 \\
\hline $\begin{array}{l}\text { Gasto no } \\
\text { programable/PIB }\end{array}$ & 15.40 & 7.13 & 6.52 & 6.20 & 5.98 & 5.68 & 5.55 & 5.43 & 5.77 & 5.24 & 5.49 & 5.52 \\
\hline \multicolumn{13}{|c|}{ Participación de la inversión pública en el gasto público } \\
\hline $\begin{array}{l}\text { Inversión física/ } \\
\text { gasto total }\end{array}$ & 15.14 & 13.16 & 11.48 & 10.89 & 10.28 & 11.21 & 12.20 & 12.44 & 12.59 & 13.61 & 13.15 & 17.78 \\
\hline $\begin{array}{l}\text { Inversión física/ } \\
\text { programable }\end{array}$ & 24.89 & 19.42 & 16.69 & 15.42 & 14.15 & 15.08 & 16.58 & 16.67 & 17.11 & 17.79 & 17.07 & 22.55 \\
\hline $\begin{array}{l}\text { Inversión física/ } \\
\text { corriente }\end{array}$ & 35.93 & 24.89 & 19.99 & 18.57 & 17.15 & 18.02 & 20.49 & 20.56 & 21.24 & 22.61 & 22.46 & 30.02 \\
\hline $\begin{array}{l}\text { Inversión física/ } \\
\text { no programable }\end{array}$ & 43.98 & 42.15 & 36.80 & 37.07 & 37.65 & 43.66 & 46.25 & 49.01 & 47.70 & 57.86 & 57.17 & 84.21 \\
\hline
\end{tabular}

a Promedio anual del periodo.

Fuente: Elaboración propia con base en: SHCP, Cuenta de la Hacienda Pública Federal, 2000 a 2009; Dirección General de Planeación Hacendaria, SHCP, base de datos, 1980-1999.

Por lo cual, realizando un análisis de correlación simple entre el PIB y la inversión pública, ${ }^{23}$ entre el PIB y la inversión privada y entre la inversión públi-

${ }^{23}$ Es importante señalar que las cifras de inversión pública consideran sólo lo destinado a la creación de infraestructura física y no consideran el gasto en infraestructura social (gasto en salud y educación, principalmente). Esto es para permitir una estimación acorde con el modelo desarro- 
ca y la inversión privada para el periodo 1980-2009, se tiene que, considerando los datos de las variables señaladas a precios nominales, existe una alta correlación entre la inversión pública y el crecimiento económico, situación similar entre esta ultima variable y la inversión privada bruta, pero, en el primer caso, el coeficiente de correlación simple es de 0.9078, mientras el coeficiente de correlación entre la inversión privada bruta y el PIB es cercano a uno (0.9934). Pero si el análisis es a precios constantes, la correlación entre el PIB y la inversión pública deja de ser significativa y sólo se mantiene con la inversión privada; lo mismo ocurre con los datos en tasas de crecimiento (véase cuadro 5).

En consecuencia, para validar nuestra hipótesis operativa para la economía mexicana durante los últimos 30 años acerca de que el gasto público productivo, transformado en inversión pública, provoca economías a escala, teniendo efectos positivos sobre el crecimiento económico, el modelo a estimar es la función producción que depende de los insumos productivos privados y del capital público (o insumo público) y está dado por la ecuación (2) de la sección anterior:

$$
Y_{t}=F\left[A K_{t p}^{\alpha}, K_{t g}^{\beta}, L_{t}^{\gamma} ; G_{t}\right]
$$

Sin embargo, la estimación directa de esta ecuación no es posible porque no se pueden obtener estimaciones consistentes para los acervos de capital público y privado, aun cuando se haga lineal a dicha ecuación. En consecuencia, siguiendo con el desarrollo del modelo, con los procedimientos y transformaciones descritas anteriormente, obtenemos una ecuación en términos de tasa de crecimiento, que se describe por la ecuación (5a):

$$
\frac{d Y}{Y} \equiv \frac{\dot{Y}}{Y} \equiv y=\alpha(G) \frac{d K}{Y}+\beta(G) \frac{d L}{Y}+\theta(G)\left(\frac{\dot{G}}{Y}\right)
$$

Esta ecuación representa un modelo de crecimiento del producto, $y$, que está en función de la tasa de crecimiento de la relaciones capital-producto $(k)$, trabajo-producto $(l)$, y del flujo del gasto público que derrame el sector público en actividades productivas (inversión física bruta del sector público), aunque el problema de estimación de los insumos permanece. Por tanto, para resolver este

llado, pues de lo contrario, para captar los efectos tanto de la inversión pública física como de la inversión social sobre el crecimiento económico, es conveniente trabajar dentro de un marco de optimización intertemporal con efectos retardados para la última variable, cuestión que no se considera aquí, pero que sí constituye un tema a investigarse en el futuro. 


\section{Cuadro 5. Evolución de la inversión en México, 1980-2009}

(Miles de millones de pesos a precios de 2003)

\begin{tabular}{|c|c|c|c|c|c|c|c|c|}
\hline Año & PIB & \begin{tabular}{|l|} 
Tasa de \\
crecimiento \\
(porcentaje)
\end{tabular} & $\begin{array}{l}\text { Inversión } \\
\text { pública }\end{array}$ & \begin{tabular}{|l|} 
Tasa de \\
crecimiento \\
(porcen- \\
taje)
\end{tabular} & $\begin{array}{l}\text { Proporción } \\
\text { respecto al } \\
\text { PIB }\end{array}$ & $\begin{array}{l}\text { Inversión } \\
\text { privada }\end{array}$ & \begin{tabular}{|l|} 
Tasa de \\
crecimiento \\
(porcen- \\
taje)
\end{tabular} & $\begin{array}{l}\text { Propor- } \\
\text { ción } \\
\text { respecto } \\
\text { al PIB }\end{array}$ \\
\hline 1980 & 4362.05 & 9.48 & 328.43 & 74.30 & 7.53 & 1124.07 & 6.00 & 25.77 \\
\hline 1981 & 4733.95 & 8.53 & 479.78 & 46.09 & 10.13 & 1180.29 & 5.00 & 24.93 \\
\hline 1982 & 4709.29 & -0.52 & 357.65 & -25.46 & 7.59 & 1017.65 & -13.78 & 21.61 \\
\hline 1983 & 4545.10 & -3.49 & 251.74 & -29.61 & 5.54 & 759.56 & -25.36 & 16.71 \\
\hline 1984 & 4700.13 & 3.41 & 228.54 & -9.22 & 4.86 & 803.50 & 5.78 & 17.10 \\
\hline 1985 & 4802.95 & 2.19 & 245.34 & 7.35 & 5.11 & 866.70 & 7.87 & 18.05 \\
\hline 1986 & 4655.07 & -3.08 & 182.25 & -25.72 & 3.91 & 871.87 & 0.60 & 18.73 \\
\hline 1987 & 4735.25 & 1.72 & 183.43 & 0.65 & 3.87 & 830.62 & -4.73 & 17.54 \\
\hline 1988 & 4791.81 & 1.19 & 147.29 & -19.70 & 3.07 & 887.54 & 6.85 & 18.52 \\
\hline 1989 & 4992.99 & 4.20 & 129.05 & -12.39 & 2.58 & 861.18 & -2.97 & 17.25 \\
\hline 1990 & 5246.05 & 5.07 & 162.18 & 25.67 & 3.09 & 937.97 & 8.92 & 17.88 \\
\hline 1991 & 5467.55 & 4.22 & 183.39 & 13.08 & 3.35 & 1019.84 & 8.73 & 18.65 \\
\hline 1992 & 5665.95 & 3.63 & 190.49 & 3.87 & 3.36 & 1110.45 & 8.88 & 19.60 \\
\hline 1993 & 5776.46 & 1.95 & 151.44 & -20.50 & 2.62 & 978.72 & -11.86 & 16.94 \\
\hline 1994 & 6031.51 & 4.42 & 184.77 & 22.01 & 3.06 & 1063.13 & 8.62 & 17.63 \\
\hline 1995 & 5659.55 & -6.17 & 145.65 & -21.17 & 2.57 & 832.82 & -21.66 & 14.72 \\
\hline 1996 & 5951.20 & 5.15 & 162.93 & 11.87 & 2.74 & 968.55 & 16.30 & 16.27 \\
\hline 1997 & 6354.22 & 6.77 & 186.75 & 14.62 & 2.94 & 1144.81 & 18.20 & 18.02 \\
\hline 1998 & 6665.99 & 4.91 & 179.73 & -3.76 & 2.70 & 1287.68 & 12.48 & 19.32 \\
\hline 1999 & 6924.18 & 3.87 & 163.33 & -9.12 & 2.36 & 1355.14 & 5.24 & 19.57 \\
\hline 2000 & 7381.31 & 6.60 & 177.17 & 8.47 & 2.40 & 1457.73 & 7.57 & 19.75 \\
\hline 2001 & 7369.72 & -0.16 & 169.47 & -4.34 & 2.30 & 1362.31 & -6.55 & 18.49 \\
\hline 2002 & 7430.65 & 0.83 & 167.29 & -1.29 & 2.25 & 1321.93 & -2.96 & 17.79 \\
\hline 2003 & 7555.80 & 1.68 & 187.27 & 11.94 & 2.48 & 1430.89 & 8.24 & 18.94 \\
\hline 2004 & 7861.68 & 4.05 & 201.71 & 7.71 & 2.57 & 1548.54 & 8.22 & 19.70 \\
\hline 2005 & 8113.68 & 3.21 & 215.96 & 7.07 & 2.66 & 1638.48 & 5.81 & 20.19 \\
\hline 2006 & 8513.90 & 4.93 & 234.45 & 8.56 & 2.75 & 1777.02 & 8.46 & 20.87 \\
\hline 2007 & 8798.34 & 3.34 & 266.91 & 13.85 & 3.03 & 1879.35 & 5.76 & 21.36 \\
\hline 2008 & 8929.46 & 1.49 & 280.10 & 4.94 & 3.14 & 1971.29 & 4.89 & 22.08 \\
\hline 2009 & 8345.65 & -6.54 & 387.76 & 38.44 & 4.65 & 1820.11 & -7.67 & 21.81 \\
\hline
\end{tabular}

Fuente: Elaboración propia con base en: INEGI, Sistema de Cuentas Nacionales de México varios años; SHCP, Cuenta de la Hacienda Pública Federal, 2000 a 2009; Dirección General de Planeación Hacendaria, SHCP base de datos. 
dilema y formular una ecuación de regresión susceptible de ser estimada, es necesario transformar $(5 a)$ en $(5 b)$ :

$$
\frac{d Y}{Y} \equiv \frac{\dot{Y}}{Y} \equiv y=\alpha\left(\frac{I}{Y}\right)+\beta \frac{d L}{Y}+\theta d\left(\frac{G}{Y}\right),
$$

donde se considera a los flujos de inversión pública y privada ( $I$ y $G$ ) como variables proxi (indicador indirecto) de los acervos de capital utilizados en la producción. Asimismo, si a la transformación de la ecuación inicial ${ }^{24}$ se le toman logaritmos y se le diferencia respecto al tiempo, para posteriormente dividir el lado derecho de la ecuación entre las variables pertinentes, podemos formular una función de producción dinámica simple y general del modelo de crecimiento de la economía mexicana, que exprese las variables pertinentes en términos de sus tasas de cambio porcentuales y cuya especificación es la siguiente:

$$
d y_{t}=a+\alpha d i_{t}+\beta d l_{t}+\theta d g_{i p t}+e_{t},
$$

donde las letras en minúscula representan los logaritmos de las variables y, por tanto, $d y_{t}$ representa el cambio porcentual anual de la tasa de crecimiento del producto interno bruto (a precios de 2003). Dada la falta de estimaciones consistentes de la fuerza de trabajo empleada en la economía mexicana, $d l_{t}$ es el cambio porcentual anual de la tasa de crecimiento de la población económicamente activa, como una variable proxi del insumo laboral; $d i_{t}$ y $d g_{i p t}$ se refieren, respectivamente, a los cambios porcentuales anuales de las tasas de crecimiento de la formación bruta de capital fijo y del gasto del sector público en inversión física, como variables proxi de la inversión privada y pública, de cuyos flujos se conforman el acervo de capital tanto privado como público, necesarios para la producción del producto total de la economía; y $e_{t}$ es un error normalmente distribuido.

Los coeficientes de la ecuación (9) representan los cambios porcentuales estimados en el PIB real asociado con el cambio porcentual dado en las tasas de crecimiento de las variables consideradas. Conforme el planteamiento teórico desarrollado en la sección anterior, tanto $\alpha$ como $\beta$ se esperan positivos, mientras que el signo de $\theta$ puede ser positivo o negativo, dependiendo de si el cambio porcentual anual de la tasa de crecimiento del gasto del sector público en inver-

${ }^{24}$ Dada en este caso por la ecuación (5) del modelo de la sección anterior. 
sión física es complemento o sustituto del gasto en inversión del sector privado para la formación bruta de capital fijo. ${ }^{25}$

La ecuación (9) fue estimada usando datos anuales de la economía mexicana durante el periodo 1980-2009, conforme a los datos del cuadro 5. Las series de datos para el PIB, población económicamente activa, formación bruta de capital fijo e inversión física, son variables proxi del producto, insumo laboral, inversión privada y pública, respectivamente, correspondientes a la ecuación estimada por mínimos cuadrados ordinarios y cuyos resultados obtenidos se muestran en el cuadro 6 .

Cuadro 6. Estimaciones de la tasa de crecimiento del producto, 1980-2009

(Resultados de la regresión por mínimos cuadrados ordinarios)

\begin{tabular}{|l|c|c|c|c|c|}
\hline \multicolumn{1}{|c|}{ Variables } & Estimación 1 & Estimación 2 & Estimación 3 & Estimación 4 & Estimación 5 \\
\hline \multirow{2}{*}{ Constante a: } & 4.378198 & 4.132184 & 4.651086 & 8.731932 & 4.390322 \\
\cline { 2 - 6 } & $(30.74609)^{a}$ & $(12.3252)$ & $(27.0999)$ & $(11.6290)$ & $(30.8208)$ \\
\hline $\begin{array}{l}\text { Formación bruta } \\
\text { de capital fijo (di). }\end{array}$ & 0.255113 & 0.836734 & n.e & n.e & 0.30484 \\
\cline { 2 - 6 } & $(4.62207)$ & $(17.8236)$ & & & $(9.8101)$ \\
\hline $\begin{array}{l}\text { Inversión fisica del } \\
\text { sector público } \\
(d g) \text {. }\end{array}$ & 0.033341 & -0.248083 & 0.150542 & -0.003766 & n.e \\
\cline { 2 - 6 } & $(1.08840)$ & $(-5.857283)$ & $(6.6131)$ & $(-0.026787)$ & \\
\hline $\begin{array}{l}\text { Población } \\
\text { economicamente } \\
\text { activa (dl). }\end{array}$ & 0.670488 & n.e & 0.9271 & n.e & 0.617807 \\
\cline { 2 - 7 } & $(11.2810)$ & & $(32.9899)$ & & $(17.8505)$ \\
\hline$R^{2}$ ajustada & 0.985178 & 0.915866 & 0.973999 & -0.035688 & 0.985077 \\
\hline $\begin{array}{l}\text { Error estándar de } \\
\text { la regresión. }\end{array}$ & 0.028209 & 0.067207 & 0.037361 & 0.235802 & 0.028305 \\
\hline D.W. & 0.711417 & 0.79124 & 0.699832 & 0.032653 & 0.715884 \\
\hline F-stat & 643.5244 & 158.845 & 544.1814 & 0.000718 & 958.143 \\
\hline
\end{tabular}

${ }^{a}$ Los datos entre paréntesis son los estadísticos $t$.

Si consideramos los resultados obtenidos por los estadísticos $R^{2}$ y $F$, correspondientes a la regresión en general, y $t$ de Student, relativos a los coeficientes de determinación, de cada una de las estimaciones realizadas, con la excepción

${ }^{25}$ La indeterminación del coeficiente también depende, en gran medida, de si se introducen o no distorsiones dentro de la economía (por ejemplo, vía impuestos y subsidios que financien o complementen la inversión pública, respectivamente) que desplacen o no, directa o indirectamente, tanto a la inversión privada como al consumo privado en sectores como construcción, transportes o alimentación. 
de la estimación 4 que no cumple con estas características, las regresiones en general tienen un relativamente alto poder explicatorio y significación estadística. Además, el relativamente bajo error estándar de las estimaciones en sus diferentes especificaciones sugiere un buen ajuste de los datos. Sin embargo, el problema de autocorrelación de los errores está presente en todas las estimaciones, lo cual se explica, por una parte, por la utilización de variables proxi en las estimaciones de la ecuación, que ocasiona que los datos no puedan reflejar la esencia de las relaciones propuestas y, por la otra, porque se tiene una estructura de datos que siguen un proceso autorregresivo de primer orden, producto de que las variables están ligadas entre sí por una tendencia lineal con movimientos compensados, por lo cual la ecuación (9) puede ser estimada por mínimos cuadrados ordinarios sin necesidad de construir un modelo dinámico, pero con el conocimiento de que se tiene una estimación insesgada pero ineficiente, evitándose una regresión espuria. Cabe mencionar que la estimación realizada con autocorrelación de los errores nos permite mostrar en este caso que ni la inversión pública ni la privada son los determinantes fundamentales del crecimiento económico de largo plazo, sino que son las deficiencias estructurales que aquejan a la economía mexicana las que determinan la tendencia del crecimiento del producto.

Bajo estas consideraciones, se juzgó necesario estimar, en un nivel individual, la ecuación (9) con cada uno de sus componentes para captar los efectos que cada una de las variables tiene sobre el crecimiento económico. Así, las estimaciones (1) y (3) sugieren que en el caso de la economía mexicana, la inversión pública tiene efectos positivos de corto plazo, como se suponía, pero poco significativos sobre el crecimiento económico durante el periodo considerado. El efecto mayor, por ejemplo, se da cuando la inversión privada no está presente, lo cual hasta cierto punto es lógico en virtud de que sólo el capital público actuaría en combinación con el insumo laboral para la generación del producto, por lo que puede deducirse que los efectos a escala esperados no se cumplirían, conforme la evidencia empírica, para el caso de la economía mexicana en el periodo 1980-2009. Asimismo, de la estimación de la especificación 2 del modelo empírico, se observa que la inversión pública es sustitutiva de la inversión privada sólo cuando se está en presencia de estos dos factores en el proceso productivo de la economía mexicana y complementaria, pero sin significación empírica, en los otros casos.

En cambio, conforme a las estimaciones (1) (2) y (5), la inversión privada muestra efectos positivos de corto plazo sobre el crecimiento de la producción, con significancia estadística para su coeficiente. Sin embargo, habría que 
destacar que si la inversión privada actúa junto con los insumos laboral y público o con el laboral solamente, su efecto sobre el crecimiento del producto sugiere, por ejemplo, que un incremento porcentual anual de $10 \%$ en la inversión privada durante el periodo corriente generará cuando mucho $3 \%$ en el crecimiento porcentual anual de la producción. De igual manera, destaca la evidencia empírica resultante para la economía mexicana de que si sólo actuaran tanto la inversión privada como la pública como factores productivos, los efectos de ambos serían contradictorios entre sí, no cumpliéndose con ello la hipótesis de complementariedad de la inversión pública sobre la inversión privada para el caso de la economía mexicana durante el periodo 1980-2009. Sin embargo, esto no es más que un reflejo de deficiencias estructurales en el aparato productivo de la economía mexicana durante los últimos 30 años, provocado por la inefectividad del gasto de inversión, tanto público como privado, ${ }^{26}$ por lo cual la política gubernamental ha de ser redefinida en su función de asignar los recursos que tiene a su disposición manifestados en su política de gasto público.

\section{CONCLUSIONES}

Dados los resultados empíricos obtenidos para la economía mexicana en el periodo 1980-2009, parecería darse por muerto el argumento que se deduce a partir del modelo desarrollado de que el crecimiento y la inversión dependen no tanto de la capacidad de generar ahorro, sino de que el gobierno establezca las condiciones propicias para la inversión productiva generadora de riqueza, en tanto que la eficacia de las acciones de la política económica para impulsar el crecimiento económico depende no tanto de su efecto sobre el ahorro sino del que se tenga sobre la inversión. Sin embargo, esto implicaría reconocer que el gasto público productivo, ya sea por inversión física, como fue el caso que se manejó en el presente trabajo, o en capital humano (gasto social), dentro de la economía mexicana no genera riqueza en tanto no contribuya a incrementar las oportunidades

\footnotetext{
${ }^{26}$ Esta inefectividad estructural de la inversión privada y pública radica, por un lado, en el freno de la capacidad instalada por el decrecimiento de inversiones netas debido a la capacidad limitada de talento, experiencia y espíritu empresarial y aversión al riesgo natural de los inversionistas privados, por el cambio sobre la función del sector público en la economía iniciada en la década de los ochenta, y por el estancamiento e inestabilidad económica provocada por los manejos erróneos de la política económica. Estos factores han limitado la capacidad para absorber los beneficios del gasto público productivo en la generación de crecimiento económico y ampliación de capacidad productiva de la economía mexicana en los pasados 30 años.
} 
de inversión rentables conseguibles por medio del crecimiento económico mediante una composición del gasto público que favorezca la creación de infraestructura económica y social, y no del gasto improductivo, como ha venido ocurriendo desde principios de la década de los ochenta del siglo pasado, como fue mostrado en los cuadros 3 y 4.

En esta circunstancia, el gasto público no será productivo ni generador de riqueza si se canaliza como desperdicio en usos no rentables en el nivel macroeconómico. Este desperdicio se refleja en que dicho gasto se utiliza más para financiar un mayor consumo, público y/o privado, que para lograr una mayor productividad de la inversión, que puede darse, entre otras medidas colaterales, por medio del fomento de la inversión productiva, pública o privada, no sustitutiva, dirigiéndola específicamente a la creación de infraestructuras económicas y sociales. Por tanto, las acciones de política económica deben estar encaminadas a que se gaste bien más que a cuánto se gasta.

Lo anterior significa que hay otro camino para enfrentar situaciones estructurales que frenan la creación de riqueza y no sólo el tradicional basado en el diseño de políticas de fomento al ahorro que, en lugar de incrementar, estrangulan el crecimiento económico, sobre todo de las pequeñas economías emergentes en crisis, como lo evidencia la economía mexicana durante los pasados 30 años. Sin embargo, a pesar de ello, no está cerrado el círculo respecto a los determinantes del crecimiento, quedando al menos abierta la siguiente pregunta al respecto: ¿Sólo la reorientación del gasto público a actividades productivas es suficiente para un crecimiento sostenido? Como se ha mostrado en los resultados empíricos, para la economía mexicana en los últimos 30 años, ese es el desafío que hay que seguir escudriñando, porque teóricamente, como se ha mostrado, es plausible que el gasto público productivo sea el factor que impulse el pleno aprovechamiento del potencial de crecimiento.

\section{REFERENCIAS BIBLIOGRÁFICAS}

Albala-Bertrand, J. M., y E. C. Mamatzakis (2001), "Is Public Infraestructure Productive? Evidence from Chile", Applied Economic Letters, Vol. 8, pp. 195-199.

Arrow, K. J., y M. Kurz (1970), Public Investment, the Rate of Return and Optimal Fiscal Policy, Johns Hopkins University.

Aschauer, David (1989a), "Is Public Expenditure Productive?", Journal of Monetary Economics, núm. 23, Vol. 2, pp. 177-200. 
Aschauer, David (1989b), "Does Public Capital Crowd Out Private Capital?", Journal of Monetary Economics, Vol. 1, núm. 24.

(1989c), "Public Investment and Productivity Growth in the Group of Seven", Economic Perspectives, Vol. 13, septiembre, pp. 17-25.

Bacha, Edmar L. (1990), “A Three-Gap Model of Foreign Transfer and the GDP Growth Rate in Developing Countries", Journal of Development Economics, Vol. 32, núm. 2.

Barro, Robert J. (1990), "Goverment Spending in a Simple Model of Endogenous Growth", Journal of Political Economy, octubre, pp. 103-125.

Barth, James, y Joseph J. Cordes (1980), "Substitutability, Complementarity, and the Impact of Government Spending on Economic Activity", Journal of Economic and Bussines, Vol. 3, primavera, pp. 235-242.

Devarajan, S., y H. Zou (1994), “Does public Investment Promote Economic Growth?”, The Hong Kong University of Science and Technology, mimeografiado.

Edwards, Sebastian (1989), "Structural Adjustment Policy in Heavily Indebted Countries", Developing Country Debt and the World Economy, The University of Chicago Press.

Esfahani, Hadi S., y María Teresa Ramírez (2003), “Institutions, Infrastructure, and Economic Growth", Journal of Development Economics, Vol. 70, pp. 443-477.

García-Alba Iduñate, Pascual, y Javier Soto (2004), "La función del tipo de cambio y el ahorro interno en el crecimiento económico", El nuevo milenio mexicano, UAM.

Gramlich, Edward M., (1994), "Infraestructure Investment: A Review Essay", Journal of Economic Literature, Vol. 32, septiembre, pp. 1176-1196.

Fishlow, Albert (1990), “The Latin America State", Journal of Economic Perspectives, verano, pp. 61-74.

Hernández M., José Luis (2009), “La composición del gasto público y el crecimiento económico", Análisis Económico, núm. 55, primer cuatrimestre, pp. 77-102.

Holtz-Eakin, Douglas (1992), "Public Sector Capital and the Productivity Puzzle", Working Paper No. 4144, National Bureau of Economic Research.

(1993), "New Federal Spending for Infrastructure: Should We Let this Genie Out of the Bottle?", Economics Public Policy Brief Archive 4, The Jerome Levy Economics Institute of Bard College, pp. 31-46.

Lächler, Ulrich, y David A. Aschauer (1998), "Public Investment and Economic Growth in Mexico", Policy Research Working Paper 1964, Banco Mundial.

Lin, Steven A. Y. (1994), “Government Spending and Economic Growth”, Applied Economics, Vol. 26, núm. 1, enero, pp. 83-94. 
Lucas, Robert E. Jr. (1988), “On the Mechanics of Economic Development”, Journal of Monetary Economics, Vol. 22, núm. 1, pp. 3-42.

Nazmi, Nader, y M. D. Ramírez (1997), "Public and Private Investment and Economic Growth in Mexico", Contemporany Economic Policy, Vol. 15, enero, pp. 67-75.

- (2003), "Public Investment and Economic Growth in Latin America: an Empirical Test", Review of Development Economics. Vol. 7, núm. 1, pp. 115-126.

Nurske, R. (1953), Problems of Capital Formation in Under-Developed Countries, Oxford University Press.

Olson, Mancur Jr. (1996), "Big Bills Left on the Sidewalk: Why Some Nations are Rich and Others Poor", Journal of Economic Perspectives, Vol. 10, núm. 2.

Ortiz, Etelberto (2007), Políticas de cambio estructural en la economía mexicana: Evaluación y perspectivas para un nuevo proyecto de nación, UAM-X-CSH, México.

Ramírez, Miguel D. (1994), "Public and Private Investment in Mexico, 1950-90: An Empirical Analysis", Southern Economic Journal, julio, pp. 1-17.

- (2007), "A Panel Unit Root and Panel Cointegration Test of Complementary Hypothesis in the Mexican Case: 1960-2001", Atlantic Economic Journal, Vol. 33, núm, 3, septiembre, pp. 343-356.

Romer, Paul M. (1986), "Increasing Returns and Long-Run Growth", Journal of Political Economy, Vol. 94, núm. 5, pp. 1002-1038.

Scitovsky, Tibor (1954), "Two Concepts of External Economies", Journal of Political Economy, abril, pp. 143-151. 